\title{
Integrating site-specific environmental impact assessment in supplier selection: exemplary application to steel procurement
}

\author{
Andreas Schiessl, et al. [full author details at the end of the article]
}

Published online: 25 February 2020

(c) The Author(s) 2020

\begin{abstract}
In times of fast-growing stakeholder interest in sustainability, the ecological and social perspective of industrial companies and its products is gaining increasing importance. In particular, the emission of greenhouse gases (GHG) in the automotive industry has come to the forefront of public and governmental attention. The transport sector accounts for $27 \%$ of all European GHG emissions and constitutes the largest emitter of $\mathrm{CO}_{2} \mathrm{e}\left(\mathrm{CO}_{2}\right.$ equivalents) among all energy demanding technologies. Due to increasingly efficient combustion engines and technology innovation towards e-mobility, the emissions from car manufacturing gain in importance. So far little focus has been laid upon the emissions created throughout the production process in automotive supply chains from a purchasing perspective. The purchasing of raw material from environmentally efficient suppliers can constitute a possibility to significantly reduce $\mathrm{CO}_{2}$ e emissions in automotive supply chains and thus contribute to the two degrees global warming goal. Supplier selection decisions, which cover approximately $75 \%$ of the value adding process of a car, are today mainly cost and quality-driven. In order to integrate $\mathrm{CO}_{2} \mathrm{e}$ as decision criterion for supplier selections, site-specific and comparable data on $\mathrm{CO}_{2}$ e emissions from the upstream supply chain is necessary, but currently lacking. To estimate $\mathrm{CO}_{2} \mathrm{e}$ emissions of steel suppliers' production sites, a model has been developed to estimate manufacturing processes on a site-specific level without the necessity of confidential primary data. The model is applied on 22 integrated steel mills in EU-15. The results, which can be transferred and used for various products and industries, e.g. the construction industry, demonstrate the partially large disparities of manufacturing efficiency regarding $\mathrm{CO}_{2} \mathrm{e}$ emissions among steel manufacturers due to different levels of process integration and internal process know-how. A range between 1879 and 2990 ( $\mathrm{kg} \mathrm{CO} 2 \mathrm{e} / \mathrm{t}$ crude steel) has been revealed. Finally, the estimated data on $\mathrm{CO}_{2} \mathrm{e}$ performance of suppliers is applied in a case study of supplier selection of a German automobile manufacturer in order to simulate environmental as well as economic effects.
\end{abstract}


Keywords $\mathrm{LCA} \cdot \mathrm{CO}_{2} \mathrm{e} \cdot$ Carbon footprint $\cdot$ Iron-and steel industry $\cdot$ Product assessment · Credit system · Decision making - Supplier selection · Automotive industry

JEL Classification Q50 · Q51 · Q54 · Q55 · Q56 - L61 · L62

\section{Introduction}

The global governmental goals of limiting greenhouse gas emissions (expressed in units of carbon dioxide equivalents $-\mathrm{CO}_{2} \mathrm{e}$ ) and global warming to $2{ }^{\circ} \mathrm{C}$ (Jaeger and Jaeger 2010) lead to increased emphasis on the topic of $\mathrm{CO}_{2}$ emissions for various stakeholders.

In Europe, the passenger car sector alone, with 259 million registered vehicles in 2016 (European Commission 2018), accounts for $11 \%$ of the total EU emissions. The EU regulation of limiting the average fleet consumption to $95 \mathrm{gCO}_{2} / \mathrm{km}$ in 2021 (European Commission 2009), has recently been updated and now sets a limit $37.5 \%$ lower for 2030 compared to 2021 (European Commission 2019). This will provide the legal framework for accomplishing the $2{ }^{\circ} \mathrm{C}$ target and encourage the quick and affordable development of sustainable technologies for implementation.

Within the automotive industry, the focus regarding $\mathrm{CO}_{2}$ emissions is on the vehicle usage phase. An extension of the scope of $\mathrm{CO}_{2} \mathrm{e}$ emissions to the manufacturing process of every component in the upstream supply chain is expected and also necessary to account for the $\mathrm{CO}_{2} \mathrm{e}$ emissions of the whole supply chain. Even though currently there are no regulations for $\mathrm{CO}_{2} \mathrm{e}$ emissions for the production phase of cars, the European Political Strategy Center, the in-house think tank of the European Commission, has identified the embedded emissions for vehicle manufacturing as one future field of activity (EPSC 2016). Taking into consideration the currently ongoing technology shift from internal combustion engine vehicles (ICEV) towards battery electric vehicles (BEV), the focus shifts from $\mathrm{CO}_{2} \mathrm{e}$ emissions within the use phase to the manufacturing phase. According to German Environment Agency (UBA 2016) the manufacturing phase of an ICEV, in case of a lifetime mileage of 168,000 km, has a proportionally small share of $15 \%$ of the overall $\mathrm{CO}_{2} \mathrm{e}$ emissions $(64 \%$ usephase, $17 \%$ fuel production and $4 \%$ for disposal and maintenance). In comparison to a BEV100 (electric driving range of $100 \mathrm{~km}$ ), calculated with the German energy mix, the manufacturing phase with a climate impact of $27 \%$ gains more importance (68\% energy consumption and production and 5\% for disposal and maintenance). Newly released initiatives, such as the new Volkswagen ID car project with a start of production by the end of 2019, even strive for carbon-neutrality throughout the whole product lifecycle including the manufacturing phase (Volkswagen 2019).

This change towards carbon emission efficiency or neutrality may represent a major challenge especially for the purchasing sector, as up to $75 \%$ of the value adding process of a car takes place in the upstream supply chain (Bai and Sarkis 2011; Hartley and Choi 1996). This is particularly challenging as in the past, car manufacturers have mostly been following economic preferences, combined with the satisfaction of quality requirements. The focus started to extend with social as well as environmental factors gaining importance (Büyüközkan 2012; Guinée et al. 
2011; Roy et al. 2009; Zimmer 2016; Zimmer et al. 2016). Therefore, stakeholders in supply chains are obliged to create and apply new strategies as well as methods to reduce carbon emissions.

A closer look at the material composition of passenger cars, taking the example of the Volkswagen Golf as the bestselling car in Europe in 2014, shows the important role of steel and iron (62.9\% of the car weight) among other materials used (Schmid and Zur-Lage 2014). In the iron and steel industry a certain lack of data transparency exists which can be traced back to two main aspects. Particularly in integrated iron and steel mills, there is high complexity due to the material and energy flows and the trading of intermediate products with varying levels of process depth among different manufacturer's production sites. ${ }^{1}$ Furthermore, access to sitespecific primary data is very limited due to industrial secret. In the last decade one of the most frequently used approaches to determine $\mathrm{CO}_{2} \mathrm{e}$ emissions in the steel industry has been the life cycle assessment (LCA) method (Bieda 2014; BurchartKorol 2011, 2013; Gielen and Moriguchi 2002; Huang et al. 2010), which considers all inputs and outputs related to the product system as well as the evaluation of environmental impact (Guinée et al. 2011). In the case of evaluating and comparing the environmental impact of specific steel products at site level, two particular shortcomings with LCA remain. On the one hand, a nonconformity of requirements regarding the setting of system boundaries make a comparability difficult. On the other hand, when primary data is not available, industry average data (not site-specific) are often consulted which do not allow for a site-specific differentiation (Bilec et al. 2006; Suh et al. 2004). Therefore, a comparability of specific production sites is currently not possible.

In order to reduce $\mathrm{CO}_{2} \mathrm{e}$ emissions within the manufacturing phase, the selection of more efficient suppliers may constitute a promising opportunity. Once specific limits for amounts of $\mathrm{CO}_{2} \mathrm{e}$ emitted during production and the corresponding penalties for exceeding these limits are introduced, a change in current supplier selection practices is unavoidable. Thus, a necessity for a more detailed consideration of supplier selection and development, with a focus on site-specific $\mathrm{CO}_{2}$ e performance of suppliers, may arise. Therefore, the goal of this study is to develop an approach which closes the transparency gap and thus allows for a formulation of $\mathrm{CO}_{2} \mathrm{e}$ as an additional supplier selection criteria against the background of a practical applicability in real life decision-making situations.

In the following study, the related literature in the field of supplier selection and life cycle assessment (LCA) is discussed (Sect. 2) before the research approach is defined (Sect. 3). The focus of the study lies on the description of the concept, necessary framework information, data sources and the development of the model (Sect. 4). A case study illustrates the application of the model and the derived results (Sect. 5). The paper concludes with a critical appraisal of the model and suggestions for future research (Sect. 6).

\footnotetext{
${ }^{1}$ Site and plant are used synonymously in the following.
} 


\section{Literature review}

\subsection{Green supplier selection}

Supplier selection plays a key role in managing supply chains (Hashemi et al. 2015; Hsu et al. 2013; Seuring and Müller 2008; Verma and Pullman 1998; Zimmer et al. 2016). Decisions in supplier selection require simultaneous evaluations from multiple viewpoints, whilst reflecting upon trade-offs among criteria (Chai et al. 2013; Kim and Wagner 2012). The goal is to select the supplier which meets the requirement of multiple, both qualitative and quantitative criteria, best (Arikan 2015; Nielsen et al. 2014). Before making a final selection, companies need to identify the needs and specifications, ultimately formulating criteria as to evaluate and qualify suppliers' performance (Igarashi et al. 2013; Zimmer et al. 2016).

During the 1980s and 1990s the first actions towards green supplier management and more specifically green supplier selection appeared and its importance has constantly been growing ever since (Dowlatshahi 2000; Igarashi et al. 2013). Research primarily focuses on the final selection stage and the additional process of weighting decision criteria (Igarashi et al. 2013; Zimmer et al. 2016). According to Zimmer et al. (2016), mathematical analytical, multi-criteria decision analysis and artificial intelligence approaches have been most frequently employed. Among them, Fuzzy Logic, AHP, ANP, DEA and TOPSIS are the most consulted methods. From a data perspective, the majority of approaches identified in the overall area of supplier selection concentrates on expert opinions (Zimmer et al. 2016). In terms of performance data for the supplier selection, however illustrative, simulated data is primarily used due to restricted accessibility of validated supplier data (Azadnia et al. 2015).

The research on criteria formulation phase, as part of sustainable or green supplier selection process is however scarce. In a literature review study by Zimmer et al. (2016) only eight papers could be identified using decision making methods, while others deal with the application of various criteria from a generic consideration. The revealed single methods comprise Delphi and Ishikawa-Diagram (qualitative methods) as well as rough set theory and fuzzy logic (artificial intelligence methods). The most widely used environmental decision criteria for supplier selection is the application of environmental management systems. Further environmental decision criteria involve environmental policies, environmental planning, product design for environment or the implementation of ISO 14001 certifications separately or as sub-criteria of environmental management systems (Govindan et al. 2015; Suraraksa and Shin 2019).

Despite this development towards environmental decision making, the specific research on $\mathrm{CO}_{2}$ as one of diverse green selection criteria is still scarce (Govindan et al. 2015; Karsak and Dursun 2016; Nielsen et al. 2014; Zimmer et al. 2016). Moreover, investigations on economic effects resulting from green supply chain management activities are absent (Ahi and Searcy 2015; Igarashi et al. 2013). 


\subsection{Life cycle assessment in supplier selection}

Only since the last years, first approaches have been presented, which address environmental criteria in a more quantitative way by means of life cycle analysis (LCA). This works in combination with specific modelling approaches for supplier selection in a multi-criteria environment.

Boosothonsatit et al. (2012) combined two approaches, fuzzy goal programming (FGP) and min-max operator and system dynamic (SD) simulations for green supplier selection. Among the usage of classical criteria such as cost and lead time, environmental impact is considered, which is derived from a simplified LCA database based on the Eco-indicator method. Kumar et al. (2014) developed a green data envelopment analysis (GDEA) approach, that incorporates results from a company specific LCA. The model, which uses an annual footprint for multiple products, is applied on a spare part manufacturer in the Indian automotive industry with the goal of an environmentally friendly supplier selection. Yoshizaki et al. (2014) developed a model for economic and low-carbon select suppliers based on integer programming combined with LCA. They investigated the country specific differences of supplier selection. An LCI database based on input-output tables from China and Japan is consulted to estimate environmental impact of a vacuum cleaner. The presented studies apply either average data from LCA databases for diverse, regional considerations or company-specific non-disclosed data. These approaches illustrate a first step towards the integration of $\mathrm{CO}_{2} \mathrm{e}$ performances into supplier selection. However, it does not comply with the requirements if a selection is made on site-specific performances of suppliers. In a recent study, Dong et al. (2018) analyze the generic application of LCA in decision analysis and identify LCA as a generally suitability approach to integrate environmental impacts. However, they point out several aspects, such as variations in scope, methodological differences and varying system boundaries as challenges which need to be overcome at first.

\subsection{Life cycle assessment for performance evaluation}

Since the 1980s, evaluating the environmental performance of consumer products has gained importance (Bilec et al. 2006; Guinée et al. 2011). In this context, life cycle assessment (LCA) has a widespread application today. It is used as a method for product and service design, decision making, improvement and evaluation as well as eco-labelling both in a political and business environment (Breun 2016; Hendrickson et al. 1997; Zamagni et al. 2013).

LCA constitutes a holistic approach, which quantifies environmental effects by taking the whole life cycle of a product or process (inputs and outputs from raw material exploitation to the end-of-life recycling) and the resulting burdens on the environment (Guinée et al. 1993; Hendrickson et al. 1997; Kndungu and Molavi 2014; Roy et al. 2009; Sonnemann et al. 2004; Suh et al. 2004) into account. A global standard with a general procedure including respective guidelines was published by the International Organization of Standardization (ISO) within the context of the 
Environmental Management Standards (EMS) (Suh et al. 2004). The ISO standard 14040 defines the principles of LCA, and the ISO 14044 illustrates the requirements that form the foundation for LCA studies. The proposed ISO process consists of four stages "(a) the goal and scope definition phase, (b) the inventory (LCI) analysis phase, (c) the impact assessment phase, and (d) the interpretation phase" Bilec et al. 2006; Guinée et al. 1993; International Standards Organisation 2006a, b; Klöpffer 2012). The goal definition and scoping (see Sect. 4.3.2.2) is often considered to be a crucial step within the process (Roy et al. 2009). It deals with defining the purpose, intended application, the system boundaries and the functional unit. Based on the application of the LCA a distinction can be made between two approaches, attributional and consequential LCAs (Weidema 2003). Attributional LCAs describe an isolated product system, in terms of material and energy flows directly linked to a defined inventory boundary. In contrast, consequential LCAs are characterized by dealing with the quantification of emission changes as a consequence of decisions and the resulting action (Bauer and Poganietz 2007; Brander 2017; Weidema 1993). Both approaches can be applied in retrospect, assessing past actions, and prospective consideration, whilst dealing with the assessment of possible future actions (Bauer and Poganietz 2007; Weidema 2003). In the life cycle inventory phase, all necessary data needs to be collected, which requires the most effort due to data availability and time consumption (Bieda 2014; Heijungs et al. 1992; Roy et al. 2009). The collected data regarding environmental loads (input and output materials for the production) constitutes the basis for the impact analysis including the contribution to diverse impact categories such as climate change (Sonnemann et al. 2004). In this category, the data is classified according to its global warming potential, which is expressed in $\mathrm{CO}_{2} \mathrm{e}$ (equivalents).

In the past, two methods were distinguished and frequently discussed in literature: the process method (bottom-up) and the input-output analysis (top-down). In the process method, all environmental input and output flows of product specific processes are determined and quantitatively described by a process flow diagram and the defined functional unit (Kndungu and Molavi 2014; Sonnemann et al. 2004). In contrast, the top-down input-output approach, which was developed by Leontief in 1936, assumes an existing interdependency among sectors of an economy and uses economic input-output data of a nation in combination with sector-level environmental impacts (Bilec et al. 2006; Leontief 1936; Suh et al. 2004). Whilst the process method and the input-output analysis offer a variety of opportunities, some limitations arise. When considering the quality of available data, the process method has its drawbacks (Bilec et al. 2006; Hendrickson et al. 1997; Yellishetty et al. 2011) due to its respective subjectivity in the definition of system boundaries (no method standardization), as well as the high data requirements for detailed process modelling and the associated necessary effort (Guinée et al. 1993). Due to the lack of detailed primary data, LCA databases, such as ecoinvent or GaBi (Ecoinvent 2007-2013; Gabi 2017), are most commonly used and represent industry average values for specific processes. The input-output analysis sets a whole economy as system boundary, but provides an aggregated level of data on sector-level only and is thus not suitable for a direct comparison of specific products (Bilec et al. 2006; Suh et al. 2004; Zimmer et al. 2017). Since 2000, newly developed hybrid 
methods and approaches have appeared more frequently in scientific literature (Guinée et al. 2011). They aim to combine the advantages of the bottom-up and topdown approaches in order to overcome the previously described limitations.

For a comparability of different manufacturers, the application of a classical process LCA does not appear to be appropriate, as primary data on a site-specific process level is inaccessible. Moreover, the usage of process LCA databases does not enable a site-specific consideration of environmental impacts due to industry average data-levels. The same applies for sectoral input-output datasets which represent a too aggregated level of data. In scientific literature, several papers on the application of LCA within the steel industry have been published, e.g. (Bieda 2014; Bieda et al. 2015; Burchart-Korol 2011; Cullen et al. 2012, 2012). All identified and analyzed approaches deal with the issue of environmental performance regarding greenhouse gases. However, all focus on an industry level or an in-depth examination of one-production site, with primary data from selected plants.

\section{Research approach}

Initially, systematic literature research was conducted in order to identify existing approaches on supplier selection which include environmental criteria. The main emphasis was placed on the site-specific performance assessment of $\mathrm{CO}_{2} \mathrm{e}$ and the investigation of both environmental and economic effects on decisions. As no suitable approach could be identified, the focus of the review was narrowed to methods used for criteria formulation and life cycle analysis for impact assessment of products (Sects. 2.1-2.3).

Based on the results of the desk-based research, in a first step, a multi-criteria decision analysis approach, consisting of two qualitative methods for decision support, was developed (Sects. 4.1, 4.2). In this sub-model, the analytical hierarchy process (AHP) is combined with technique for order preference by similarity to ideal solution (TOPSIS). In order to define the basis for decision making, the literature was reviewed for supplier selection criteria with experts from a German original equipment manufacturer (OEM) being consulted. Subsequently, experts from the same OEM were consulted in single, personal interviews to derive criteria preferences and the respective weightings for the AHP method by means of pairwise comparisons. Each expert opinion was investigated for judgement consistency and subsequently aggregated to group preferences. For the ranking of supplier alternatives the TOPSIS method was consulted. According to the chosen selection criteria, real-world supplier performance data was collected from the OEM for a selected mechanical component case.

In a second step, a systematic and modular LCA based approach was developed in order to create transparency of site-specific environmental performance thus to enable a comparability of steel suppliers' performances (Sects. 4.1, 4.3). The model makes use of data which was collected from publicly available sources without the dependency of primary data, which is highly restricted. In this sub-model, technical process flows are calculated (bottom-up data) and combined with site-specific top-down information on environmental impact $\left(\mathrm{CO}_{2}\right)$. The trading of intermediate products between 
different production sites and technical restrictions are also considered. The model development steps and the data results were validated with experts from a global manufacturer for steel produced in integrated iron and steel mills (Sect. 5.2).

In a third step, the results of the site-specific $\mathrm{CO}_{2} \mathrm{e}$ model (Sect. 5.1) were integrated into the developed decision support sub-model as performance data for the additional criteria $\mathrm{CO}_{2}$ e (Sect. 5.3). Consequently, a sensitivity analysis will be performed in order to evaluate the robustness of the model and to investigate its effects on current supplier selections (Sect. 5.4). Finally, by means of 'what-if' scenario simulations the dynamic behavior of the model is investigated in order to study how decisions may change when $\mathrm{CO} 2 \mathrm{e}$ is formulated and implemented as new criteria, considering both ecological as well as economic effects (Sect. 5.5).

The main contribution of this study is the creation of transparency and comparability of environmental impacts in upstream raw material supply chains, the development of a decision support model for criteria formulation and the combination of both approaches in an integrated simulation model in order to enable a reduction of GHG emissions.

\section{Integrated $\mathrm{CO}_{2} \mathrm{e}$ assessment and decision support model for supplier selections}

\subsection{Model structure}

The model for integrating site-specific environmental impact assessment in supplier selection is structured into two parts. In the following course the sub-models are addressed as sub-model for decision support and environmental performance assessment. The results of estimating the environmental performance of suppliers are integrated in the decision support model, representing the coupling point for the sub-models (see Fig. 1). The integrated model is implemented in Microsoft Excel

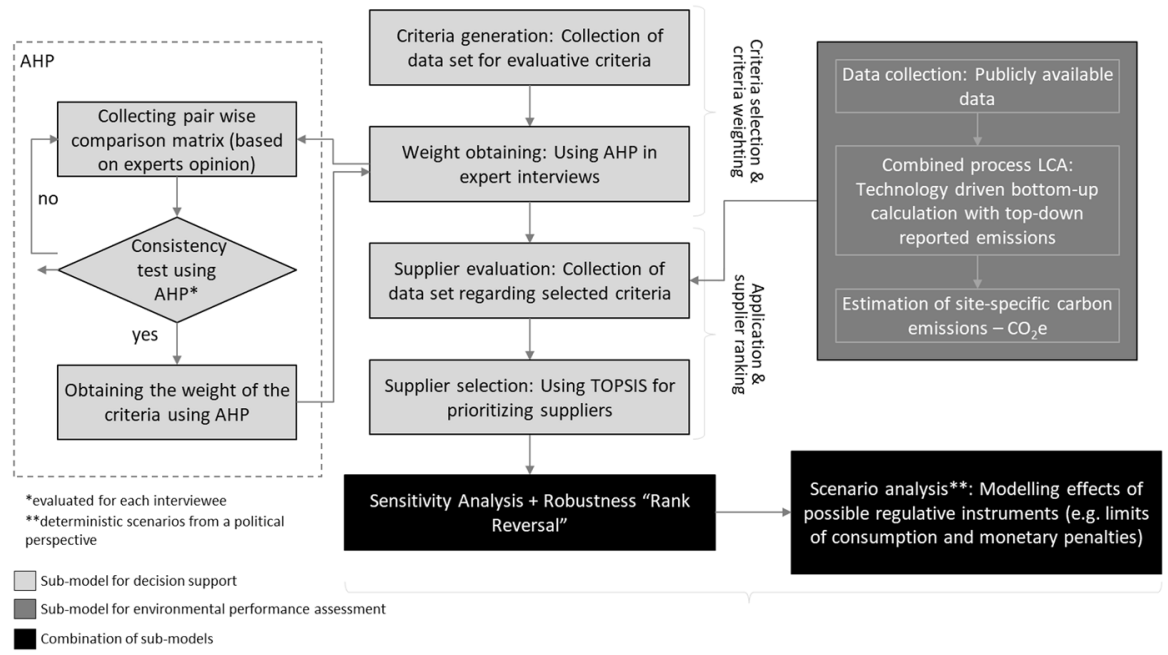

Fig. 1 Structure of the outlined model to integrate $\mathrm{CO}_{2} \mathrm{e}$ in the supplier selection process 
and allows for an easy handling for practitioners. Selection criteria, supplier performance data as well scenario simulation parameters can be adjusted according to the decision environment and user specific preferences. The sub-model for environmental performance assessment is programmed in Microsoft Visual Basic and coupled with the Microsoft Excel model. The created simplicity of the model and tool without a significant loss of data accuracy enables a user-friendly, practical application in an industrial environment. Thus, not only regular data updates (e.g. for a new time frame of the study, for plant modifications, etc.), but also the manual integration of varying primary data (e.g. material conversion rates) with the purpose of increasing data accuracy can be completed.

\subsection{Sub-model for decision support to integrate new criteria in supplier selection}

\subsubsection{Model concept}

In order to enable the formulation and integration of $\mathrm{CO}_{2} \mathrm{e}$ as supplier selection criteria, a model, which allows for the consideration of qualitative expert judgments combined with current supplier performance data, was developed.

Therefore, a mathematical analytical, MCDA approach, comprising of a combination of the Analytic Hierarchy Process (AHP), developed by Saaty (1980), and the Technique for Order Preference by Similarity to Ideal Solution (TOPSIS), developed by Hwang and Yoon (1981), was selected (see Fig. 1). AHP allows for a prioritization of conflicting criteria (tangible and intangible) or alternatives in a multiple criteria environment achieved by pair-wise comparisons. It supports decision makers by converting complex decision problems into a simplified and structured problem hierarchy (Bruno et al. 2012; Singh 2014).

However, the application of AHP for the ranking of alternatives is time extensive and difficult when several alternatives are simultaneously evaluated. In contrast, in TOPSIS all suppliers are evaluated and ranked simultaneously according to their quantitatively expressed performance score (cardinal absolute measurement) in reference to the selected set of criteria (Shih et al. 2007). In order to determine a ranking, the performance of an alternative is compared to the ideal best and ideal worst solution. The alternative with the shortest distance to the positive ideal solution and longest distance from the negative ideal solution is accordingly placed first. For a more detailed understanding of the selected approaches and their applications, reference is made to (Büyüközkan 2012; Fox et al. 2015; Hanine et al. 2016; Hwang and Yoon 1981; Saaty 1980, 2001). At this point, the two sub-models are coupled (see Fig. 1). The results of the sub-model for the estimation of site-specific $\mathrm{CO}_{2}$ e performance, which will be described in the course of this research, are integrated.

\subsubsection{Model development}

According to the motivation of the research, a hierarchical structure of the problem was developed. Therefore suitable criteria had to be selected, a pairwise comparison 
matrix to be constructed and ratio scales (weights) to be derived by the principal eigenvector method (Saaty 1980). The chosen main and sub-criteria on level one and two of the problem hierarchy (see Table 1) rely on an extensive literature research and were further verified by five experts from the purchasing division of the OEM to fit the case study (company-specific requirements). In total 41 purchasing experts from different purchasing divisions (purchasing for consumable and non-consumable resources as well as strategic purchasing division) and on various hierarchy levels (specialist buyer, team leader, department manager, senior department and division manager) were consulted in face-to-face interviews to conduct a pairwise comparison of the selected criteria. At this point, a selection of the 25 experts from the non-consumable division was made in reference to the chosen case of application (see Table 2). The criteria from the two levels, the main criteria with the according sub-criteria, are firstly evaluated by the experts (global level) and then multiplied in order to synthesize local criteria weights (Saaty 1987).

The judgments of each expert were individually checked for consistency. All judgements show a consistency ration (CR) below 10\%, which defines the acceptable limit for consistency violations (Saaty 1980). Following the single judgements were aggregated to group weights, applying the aggregation of individual judgements method (AJP) in combination with the geometric mean method (Aczél and Saaty 1983; Forman and Peniwati 1998). This approach is suitable for homogenous groups, which holds true for the selected sample of purchasing experts from the non-consumable division (Grošelj et al. 2015; Ossadnik et al. 2016; Saaty 1989).

The derived criteria weights show a continuing importance of economic and quality aspects. During the interviews it became apparent that $\mathrm{CO}_{2} \mathrm{e}$ from the manufacturing phase does not play a role in current decision making. However, due to the pairwise comparison of the applied AHP methodology, a weight of $2.67 \%$ was assigned to the new decision criteria (see Table 1), indicating a minor role of the criterion. This issue is further addressed in the context of sensitivity analysis in Sect. 5.4. The generated weights can be utilized to evaluate the supplier performance in the TOPSIS approach and to create a corresponding ranking of alternatives/suppliers. Therefore, one example part, sourced in the non-consumable division, was chosen for the case study. The performance scores per criteria of five example alternatives and respectively suppliers, were analyzed (see Table 2).

\subsubsection{First application and derivation of necessity to model site-specific $\mathrm{CO}_{2} \mathrm{e}$ performance}

At this stage a simplified material composition was applied to show the general functionality of the selection model and the further necessity for a more detailed analysis of suppliers $\mathrm{CO}_{2} \mathrm{e}$ performance. From scientific publications data on regional industry averages can only be found for some selected countries. Furthermore, the results from site-specific assessments studies only cover a few selected plants. However, variations in level of detail and setting of system boundaries, as well as the limited regional and site-specific scope do not allow the application for Europe in the chosen supplier selection example. Hence, the availability of data is limited to LCA databases which use industry averages and provide the highest degree of granularity on a regional, European 


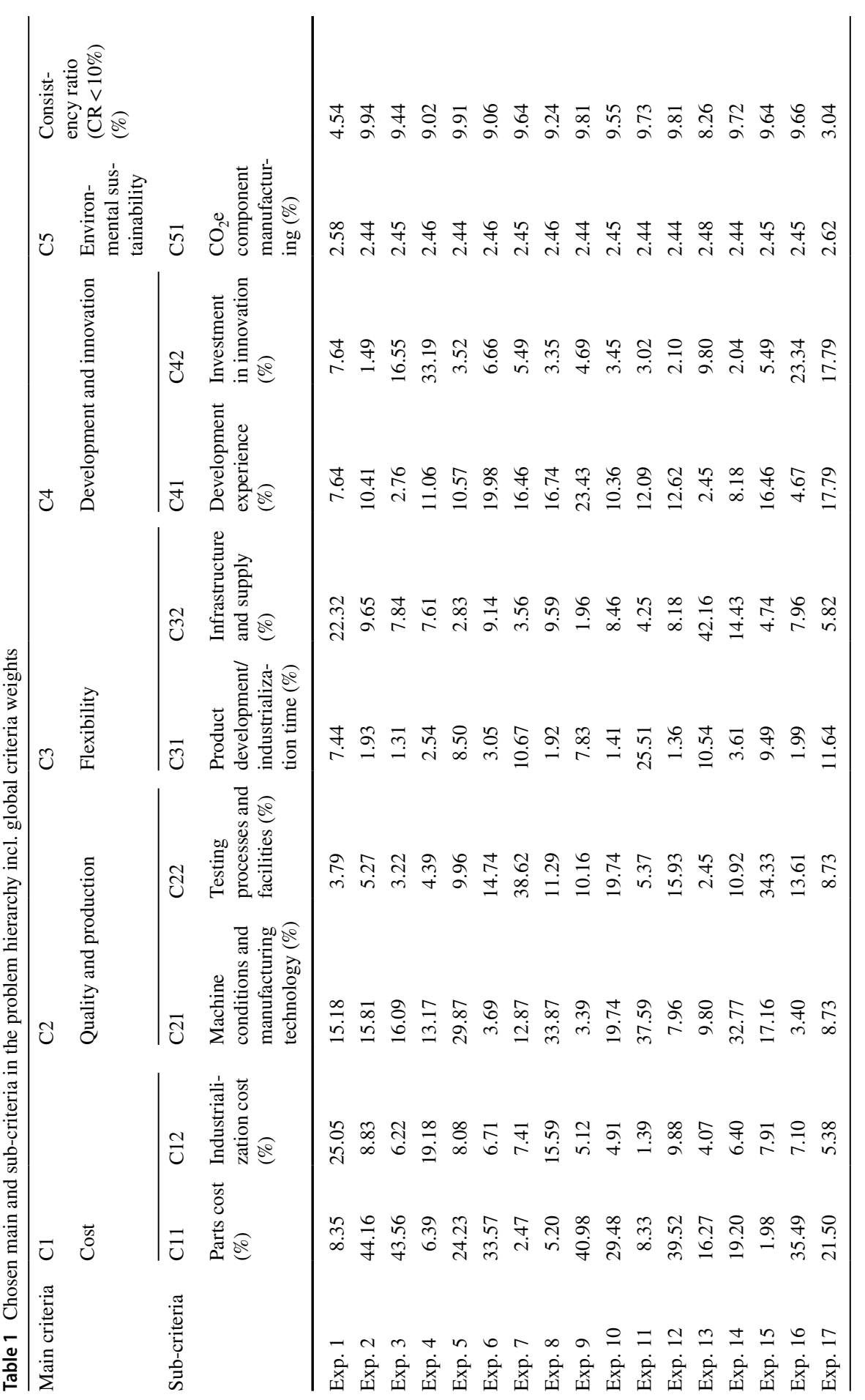




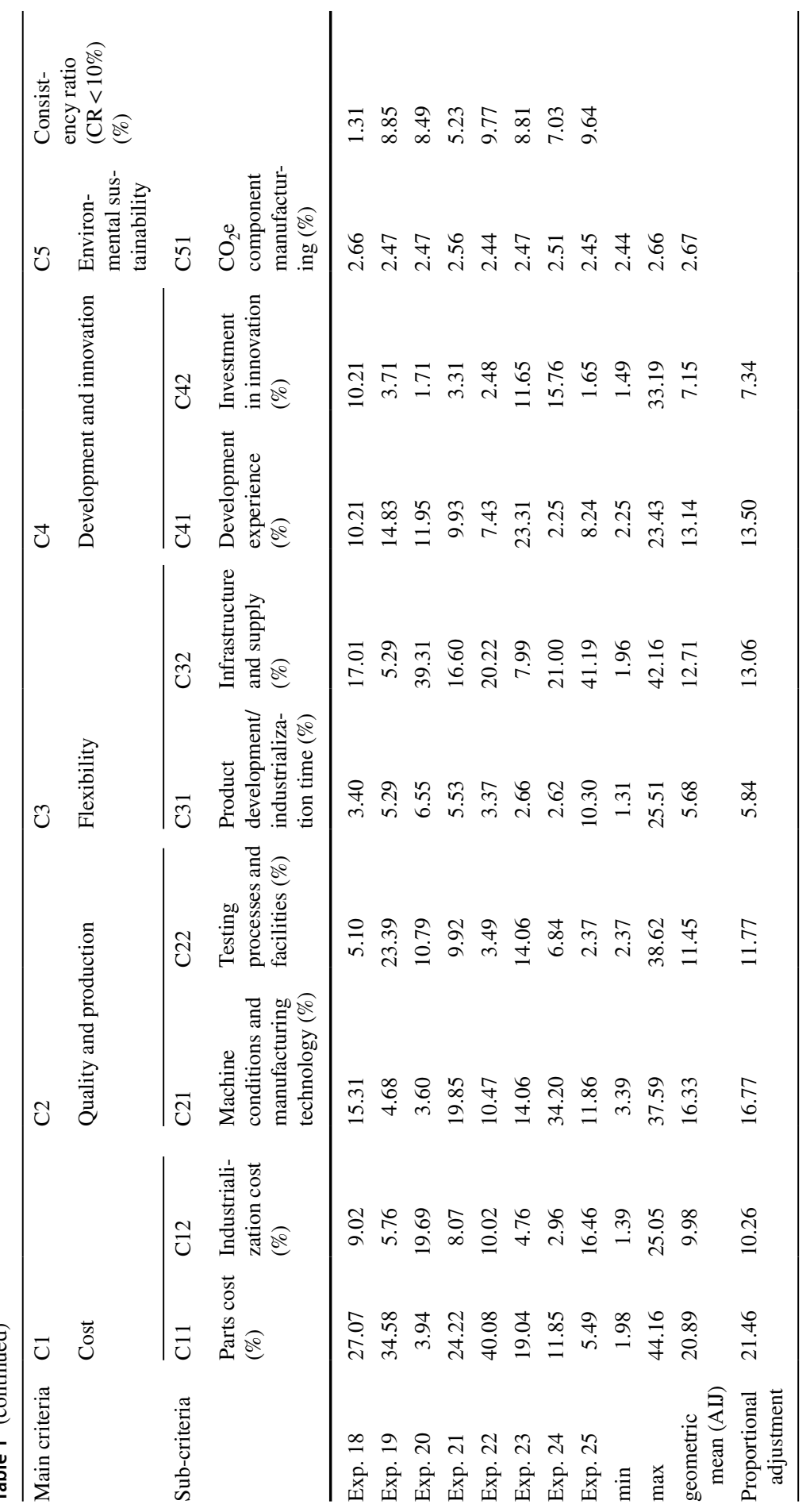




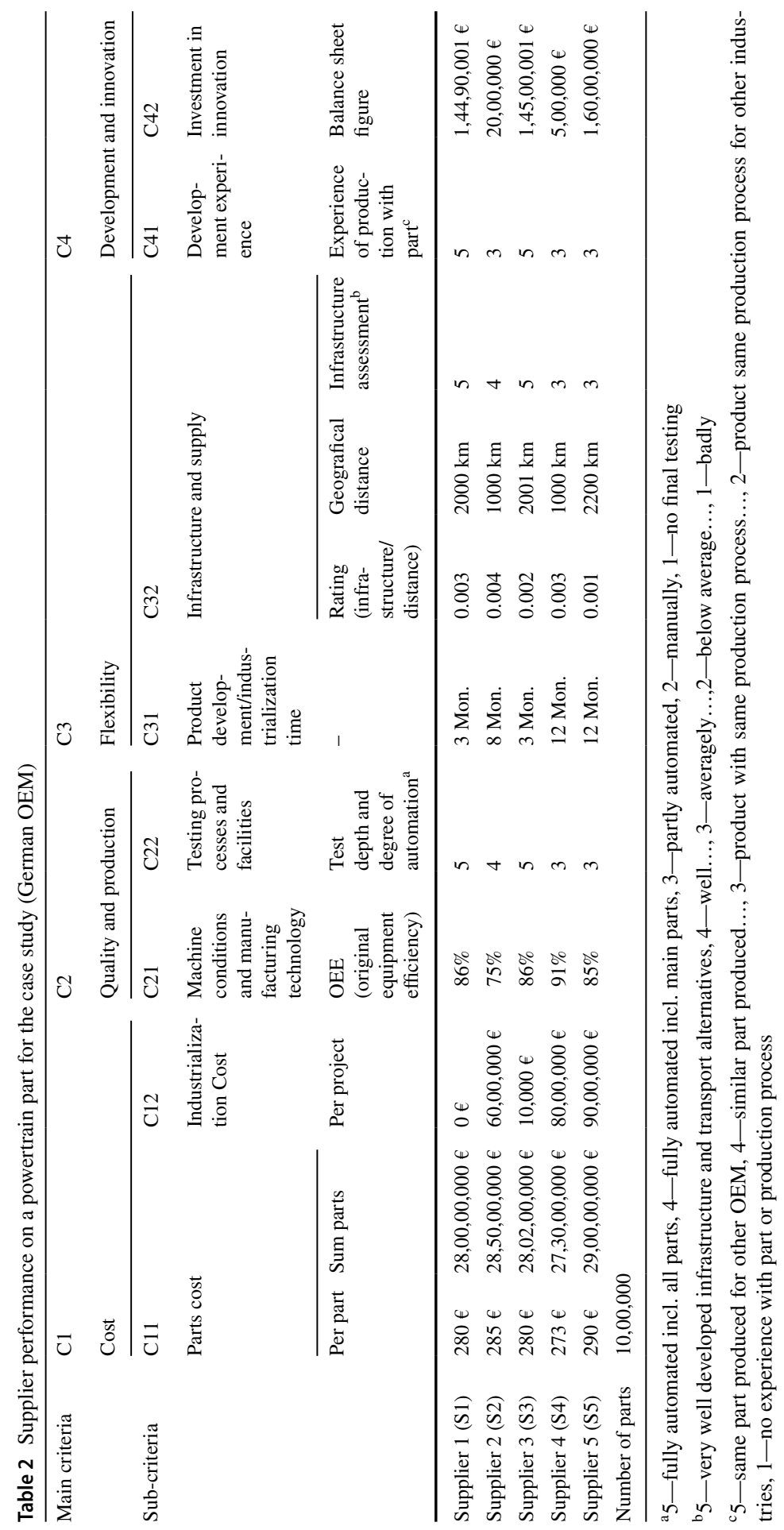



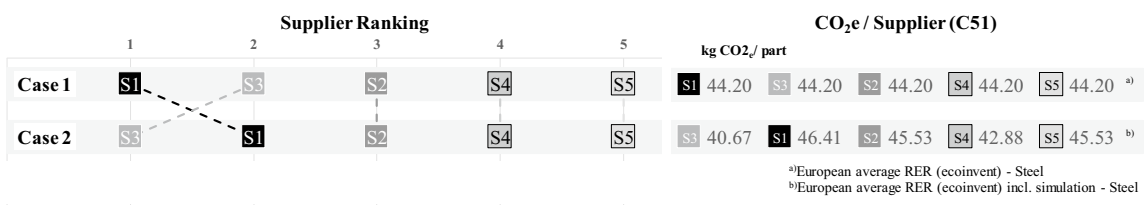

Fig. 2 Influence of $\mathrm{CO}_{2} \mathrm{e}(\mathrm{C} 51)$ on supplier ranking (Part 1)

level (RER). For the steel produced in integrated steel mills, including emissions from all upstream activities, the average cradle-to-gate value is $2408 \mathrm{~kg} \mathrm{CO}_{2} \mathrm{e} / \mathrm{t}$ crude steel (Ecoinvent 2007-2013). The selected part, with a weight of $18.36 \mathrm{~kg}$, was at this stage assumed to be produced only from crude steel. With the application of the average European value it shows an equal environmental performance score of $44.20 \mathrm{~kg} \mathrm{CO}_{2} \mathrm{e} /$ part for all suppliers (see Fig. 2, case 1). The emissions for further processing as well as transport emissions to the Tier-1 and from the Tier-1 supplier to the OEM were not considered in this study. This was due to generally small share of $\mathrm{CO}_{2} \mathrm{e}$ emissions of approximately $10 \%$ for processing and transport in proportion to the raw material production in case of primary steel (Ecoinvent 2007-2013). The first application of the AHP/TOPSIS model including environmental performance data shows the following supplier ranking: $\mathrm{S} 1 \rightarrow \mathrm{S} 3 \rightarrow \mathrm{S} 2 \rightarrow \mathrm{S} 5 \rightarrow \mathrm{S} 4$.

Currently the average European value is slightly manipulated for the five suppliers considered in this study (see Fig. 2, case 2). The average value of $2408 \mathrm{~kg} \mathrm{CO}_{2} \mathrm{e} / \mathrm{t}$ crude steel is changed by $+5 \%$ for supplier $1\left(46.41 \mathrm{~kg} \mathrm{CO}_{2} \mathrm{e} / \mathrm{part}\right)$, by $+3 \%$ for supplier 2 (45.53 $\mathrm{kg} \mathrm{CO}_{2} \mathrm{e} /$ part), by $-8 \%$ for supplier 3 (40.67 $\mathrm{kg} \mathrm{CO}_{2} \mathrm{e} /$ part), by $-3 \%$ for supplier 4 (42.88 $\mathrm{kg} \mathrm{CO}_{2} \mathrm{e} /$ part) and by $+3 \%$ for supplier 5 (45.53 $\mathrm{kg} \mathrm{CO}_{2} \mathrm{e} /$ part). The application of the manipulated performance scores leads to change in supplier ranking, S3 $\rightarrow \mathrm{S} 1 \rightarrow \mathrm{S} 2 \rightarrow \mathrm{S} 5 \rightarrow \mathrm{S} 4$ and puts supplier 3 in first position (see Fig. 2). The performance scores of supplier 1 and 3 show a deviation of only 14.13\%. This confirms and further strengthens the motivation of the research as real-world supplier selections are based on the performance of suppliers according to the site where the products are manufactured.

\subsection{Sub-model for the assessment of site-specific environmental performance}

\subsubsection{Model concept}

In addition to the classical LCA models, Breun $(2016,2017)$ developed a model to simulate metal plants on individual process level in order to evaluate future climate policies. The approach combines a non-linear programming model with an input-output model by Leontief (1936) and uses technological restrictions as well as plant specific data on GHG emissions. The newly developed approach- $\mathrm{ECCO}_{2}$ steel (evaluation tool to compare $\mathrm{CO}_{2}$ emissions of the iron and steel industry) which follows the model from Breun (2016) and Breun et al. (2017), uses however a sequential step-by-step calculation (see Sect. 4.3.2.5) in contrast to a simultaneous calculation applied by Breun (2016). It shows a lower complexity while achieving 
a similar accuracy of results. It can be considered as a combined approach based on the process LCA method, applying bottom-up and top-down site-specific data, which does not include Leontief's input-output model on an economic sector level. The model makes exclusive use of publicly available data and is thus independent of confidential company internal data. However, if primary data is available, the model allows for an easy integration and can thus enable an even more widespread, practical application. The developed approach falls into the category of attributional LCAs (see Sect. 2.3).

A schematic framework for life cycle sustainability analysis (LCSA), originally developed by Guinée et al. (2011) and further revised and modified by Zimmer et al. (2017), is ideally suited to categorize the proposed site-specific $\mathrm{CO}_{2} \mathrm{e}$ model into the range of varying LCA approaches (see Fig. 3). Whereas process LCA is usually found at the product-oriented, micro level exclusively, the presented approach extends the object of analysis as the data availability for the conduction of a site-specific process LCA is not given. In the iron- and steel industry, especially the intercompany trading of necessary intermediate products and the accompanying $\mathrm{CO}_{2} \mathrm{e}$ emissions do not allow the use of a classical LCA approach. Therefore, the object of analysis has been extended to meso, company level (Magerholm Fet 1998) by integrating reported environmental data $\left(\mathrm{CO}_{2}\right)$ on production site-specific level (see Sects. 4.3.2.4, 4.3.2.5). The boundaries between these levels are not to be seen as

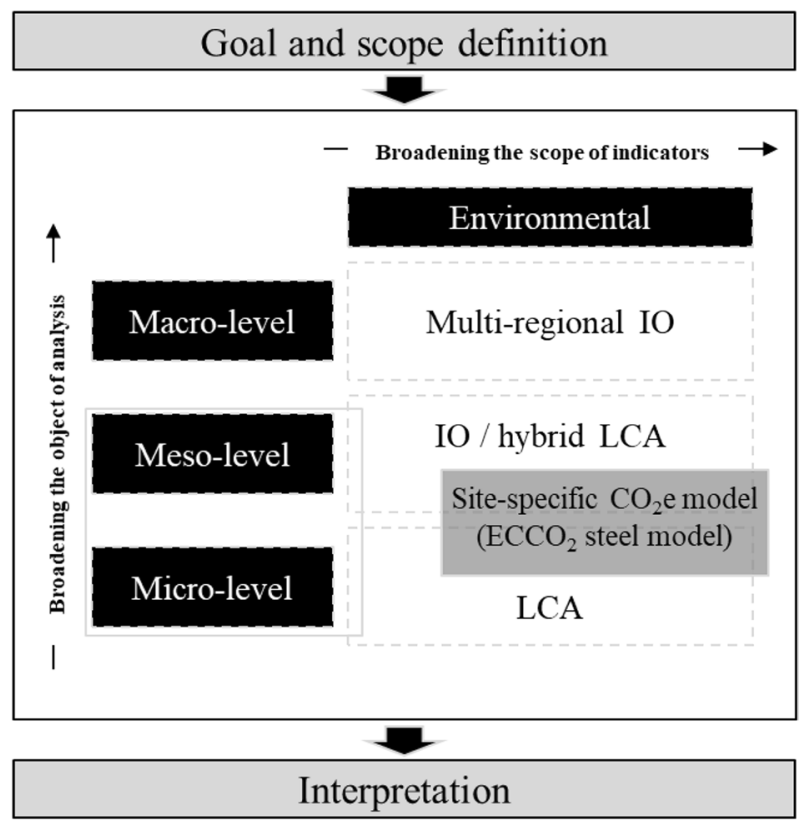

IO: Input Output Analysis

LCA: Environmental Life Cycle Assessment

$\mathrm{ECCO}_{2}$ Steel: Evaluation tool to compare $\mathrm{CO}_{2}$ emissions of the iron and steel industry

Fig. 3 LCA Framework (based on Guinée et al. (2011) and Zimmer et al. (2017)) 


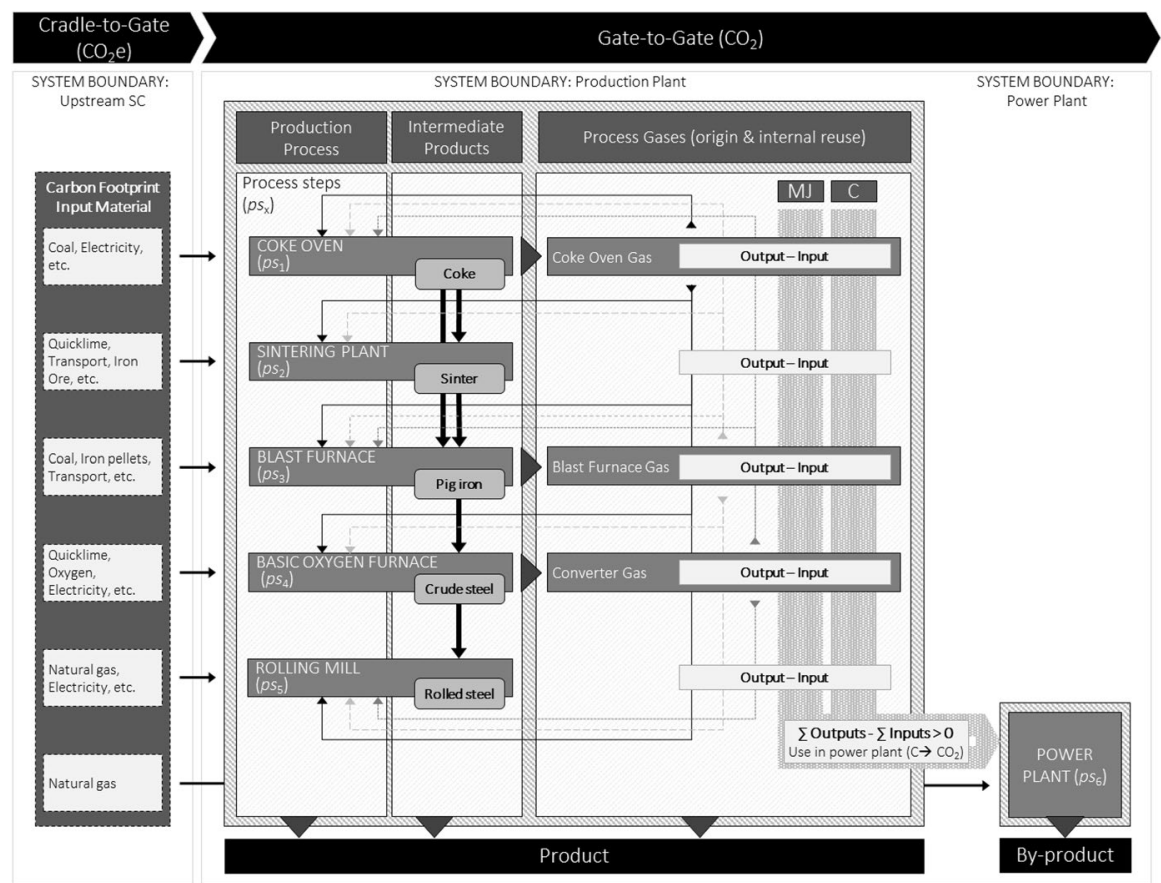

Fig. 4 Process steps of an integrated iron and steel mill including designated system boundaries and the contemplated material as well as energy flows

definite, as the application of methods or data from one level might advantageously be used on another level.

\subsubsection{Model development}

4.3.2.1 Process steps in the manufacturing process of an integrated steel mill The production of crude steel, which is primarily (70\%) conducted in integrated iron and steel mills, has the highest complexity in steel making processes (European Commission 2013) due to the high interdependency of process steps $\left(p s_{x}\right)$ as well as material and energy flows (see Fig. 4). The production process in integrated iron and steel mills centers on the blast furnace $\left(p s_{3}\right)$, where pig iron is produced on the basis of oxidic iron ore by the application of coke as a reducing agent. Liquid steel as well as certain waste and by-products, such as blast furnace slag, dust or sludge, remain after the reduction of iron ores (Das et al. 2007).

The secondary product blast furnace slag, for example as granulated blast furnace slag (GBFS), has a widespread application in various areas such as in the cement industry (Huang et al. 2016) (Siddique 2014). Iron ore is agglomerated to sinter in the sintering plant ( $\left.p s_{2}\right)$ using coke breeze as fuel (Zhou et al. 2015). It can have a significant impact on the efficiency of the sintering process depending on the size distribution of coke particles. The upstream production of coke, by the carbonization of coal in thermal decomposition, takes place in a prior process, the coke oven 
$\left(p s_{1}\right)$. By the injection of oxygen (refining) in the downstream process into the basic oxygen furnace $\left(p s_{4}\right)$ the remaining carbon content of the crude steel is reduced to less than 1\% (Worrell et al. 2009). Through the oxidation of impurities, unwanted tramp elements in the pig iron, such as silicon, sulfur and phosphor are isolated from the crude steel in a swimming layer of slag. The swimming layer of slag is separated when crude steel is tapped. According to customer requirements and material specifications (e.g. a car manufacturer), alloying elements can deliberately be added in ladle furnaces in a secondary metallurgy treatment. Finally, liquid crude steel is further processed to semi-finished products and prepared for downstream finishing operations such as forming and rolling. This is done either in ingot or in the more widespread technology of continuous casting, which represents more than $96 \%$ in Europe (World Steel Association 2013), $\left(p s_{5}\right)$. Process gases (coke oven gas: COG, blast furnace gas: BF gas, basic oxygen furnace gas: BOF gas), which are generated during the production of crude steel and can provide more than $60 \%$ of the energy demand of steel plants (World Steel Association 2019), are modelled to be internally reused as energy source at several process steps in the production plant. Furthermore, an existing surplus of gases from the production process is used for power generation in the power plant.

4.3.2.2 Scope of the site-specific $\mathrm{CO}_{2} \mathrm{e}$ approach and functional unit The scope was determined on the $\mathrm{CO}_{2}$ emissions, as they represent $98.3 \%$ of greenhouse gases (GHG) emitted in the iron- and steel production (UBA 2018a). The flow diagram, presented in Fig. 4, shows all considered process steps, gas flows and external supplies which have an impact on the site-specific $\mathrm{CO}_{2} \mathrm{e}$ emissions. For the upstream supply of raw materials all greenhouse gases were considered. Geographically, the study focuses on 22 iron and steel mills in EU-15 countries (see Fig. 5), which are suppliers to the European automotive industry. This selection of manufacturers was made based on four expert interviews from leading international Tier-1 suppliers and one OEM.

For this study, the functional unit for the quantitative reference to which a normalization of the LCI dataset has to be carried out (Roy et al. 2009; Sonnemann et al. 2004), was defined as one $t$ crude steel. This performance measure, which is the crucial concept in LCA (Bieda et al. 2015) and highlighted in the DIN ISO 14044 framework, allows a comparison (Kndungu and Molavi 2014) of the selected sample of manufacturers as crude steel is the output product of all examined sites. The model includes all emissions, intermediate products, process gases and energy supply directly related to the manufacturing of crude steel.

4.3.2.3 System boundaries The definition of the system boundaries, in combination with the functional unit enables a valid comparison of results (Tanaka 2012). This is especially important in the steel production area (Brunke and Blesl 2014) due to the complex interconnection/coupling of process steps and the existing trade of intermediate products as not all process steps are on-site (see Table 3 ) and capacity restrictions prevail. All operations that are necessary for the production of crude steel are covered within the "Production Plant" boundary (gate-to-gate). The 


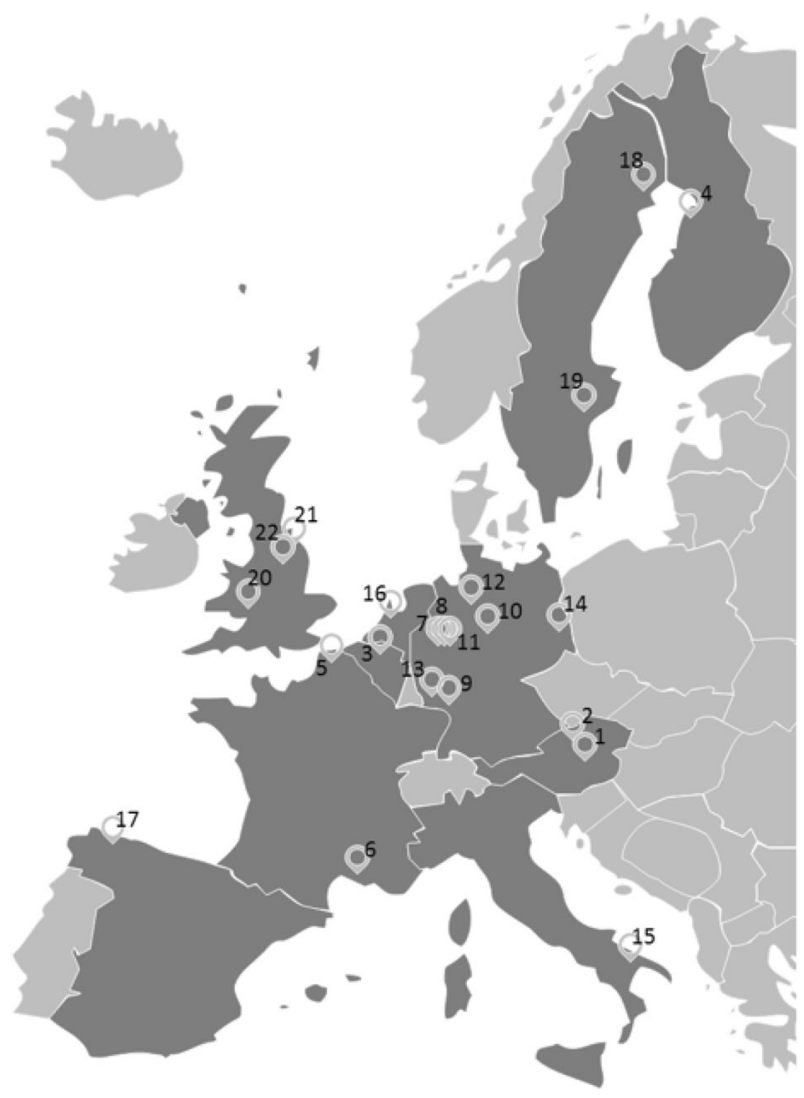

Fig. 5 Geographic location of the considered integrated iron- and steel mills in Europe

system is extended by connected power plants ("Power Plant") which are used for power generation from locally produced process gases but report $\mathrm{CO}_{2}$ emissions separately (see Fig. 4). In order to complete the environmental impact $\left(\mathrm{CO}_{2} \mathrm{e}\right)$ from the upstream supply chain, the external raw material supply was included into the product system (cradle-to-gate) by consultation of industry average values from publicly available data bases (see Sect. 4.3.2.4) as more detailed site-specific information is not available. Further secondary products, e.g. blast furnace slag, were not considered in the scope of this study, as they are not directly linked to the defined functional unit and no detailed information regarding the further processual use was available.

4.3.2.4 Data collection The LCI comprises the comprehensive gathering of data in order to estimate the site-specific environmental impact. Due to limited access to primary data in the steel industry, the collection of data was focused on publicly available data sources (reference year 2012), which are updated on a regular basis. Thus, 


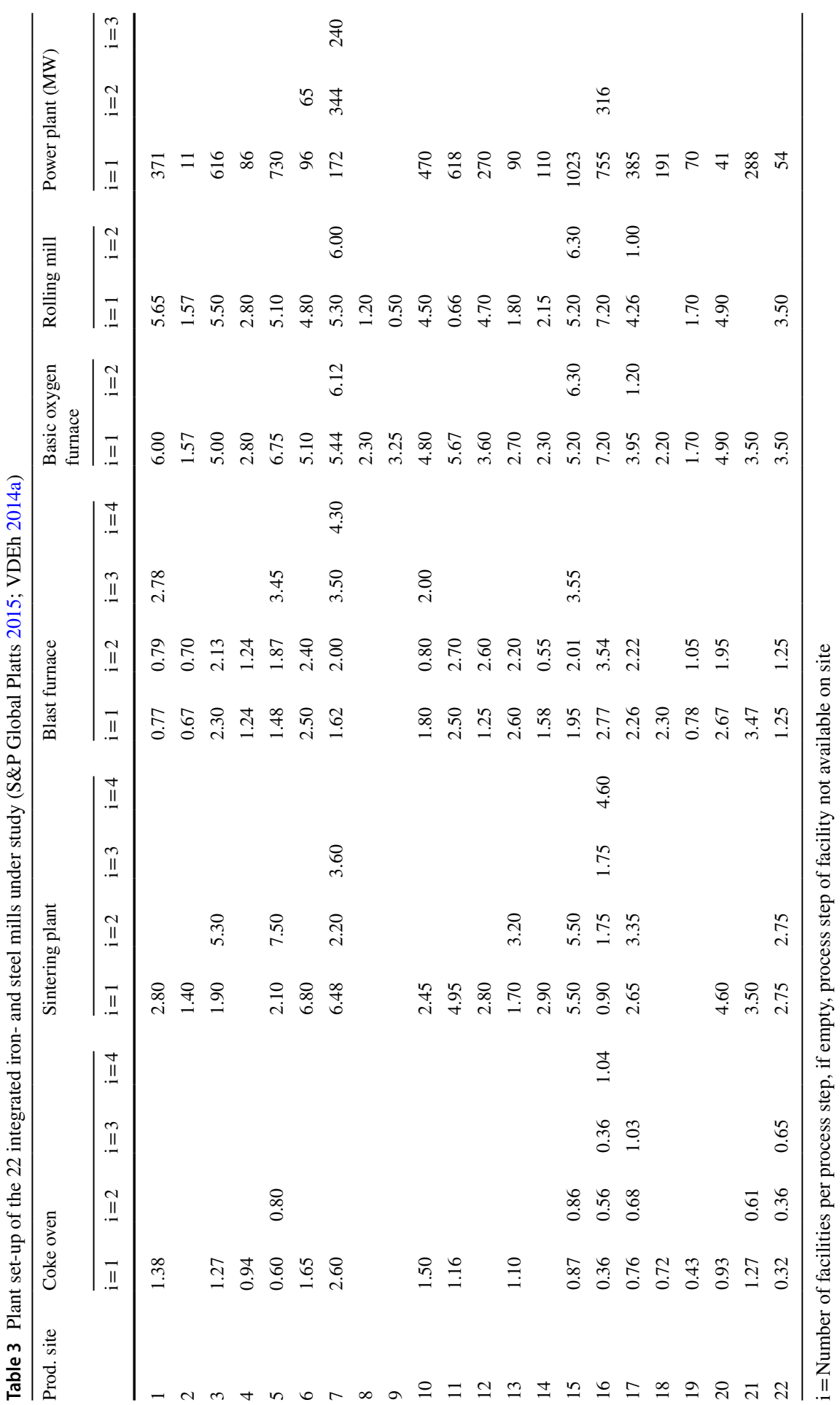


Table 4 Data sources applied

\begin{tabular}{lll}
\hline Data scope & Type of data & Source \\
\hline Plant specific data & Capacities & $\begin{array}{c}\text { PLANTFACTS data base (S\&P Global Platts 2015; } \\
\text { VDEh 2014a) } \\
\text { World electric power plants database (S\&P Global } \\
\text { Platts 2015) }\end{array}$ \\
& Production volumes & $\begin{array}{c}\text { Statistical yearbooks (VDEh 2014b) } \\
\text { Company specific reports }\end{array}$ \\
& Emissions & $\begin{array}{c}\text { European Pollution and Transfer Register E-PRTR } \\
\text { (European Environment Agency 2012) }\end{array}$ \\
& & Best Available Techniques BAT (European Com- \\
General technical parameter & Production process & mission 2013) \\
& & Non-linear programming approach (Breun 2016) \\
Country specific data & Electricity mix & German Environment Agency (UBA 2012) \\
Earbon footprint & Input material steel & Ecoinvent Data Base (Ecoinvent 2007-2013) \\
& manufacturing &
\end{tabular}

the time horizon under study can continuously be extended. Due to the Industrial Emissions Directive 2010/75/EU, each installation plant in Europe needs to apply for and receive a permit for operation which follows the best available techniques to achieve a high level of environmental protection (European Commission 2010). The published best available techniques reference document for the iron and steel industry (European Commission 2013), combined with the limited published site-specific data (see Table 4) provide the framework information for the technology-driven bottom-up calculation (see Sect. 4.3.2.5).

Regarding emission reporting, the regulation (EC) No 166/2006 of the European parliament and the council (European Commission 2006) obliges member states to annually report amounts of released air pollutants, which include the production of metals. This includes the production of pig iron or steel, rolling mills and power plants for combustion (depending on a certain production volume). This creates the basis for the top-down integration of site-specific $\mathrm{CO}_{2}$ emissions (see Sect. 4.3.2.5). For more detailed information about the data applied, please refer to "Appendix".

4.3.2.5 Site-specific $\mathrm{CO}_{2}$ e performance modelling As addressed in Sect. 4.3.2.3, several production sites under study do not have the process step to produce the compulsory intermediate products (sinter, coke) on-site but procure them externally. Furthermore, the existing procurement also includes products such as pig iron due to capacity constraints. As the amount of crude steel produced on-site requires a certain amount of intermediate products (European Commission 2013), the $\mathrm{CO}_{2} \mathrm{e}$ emissions, which are emitted during the production of intermediate products at the selling plant, need to be allocated to the site where the intermediate products are further processed. The resulting hurdle of incomparability of production plants is overcome by the integration of a credit system for procured and sold intermediate product which then allows a normalization to $\mathrm{kg} \mathrm{CO}_{2} \mathrm{e} / \mathrm{t}$ crude steel per site. 


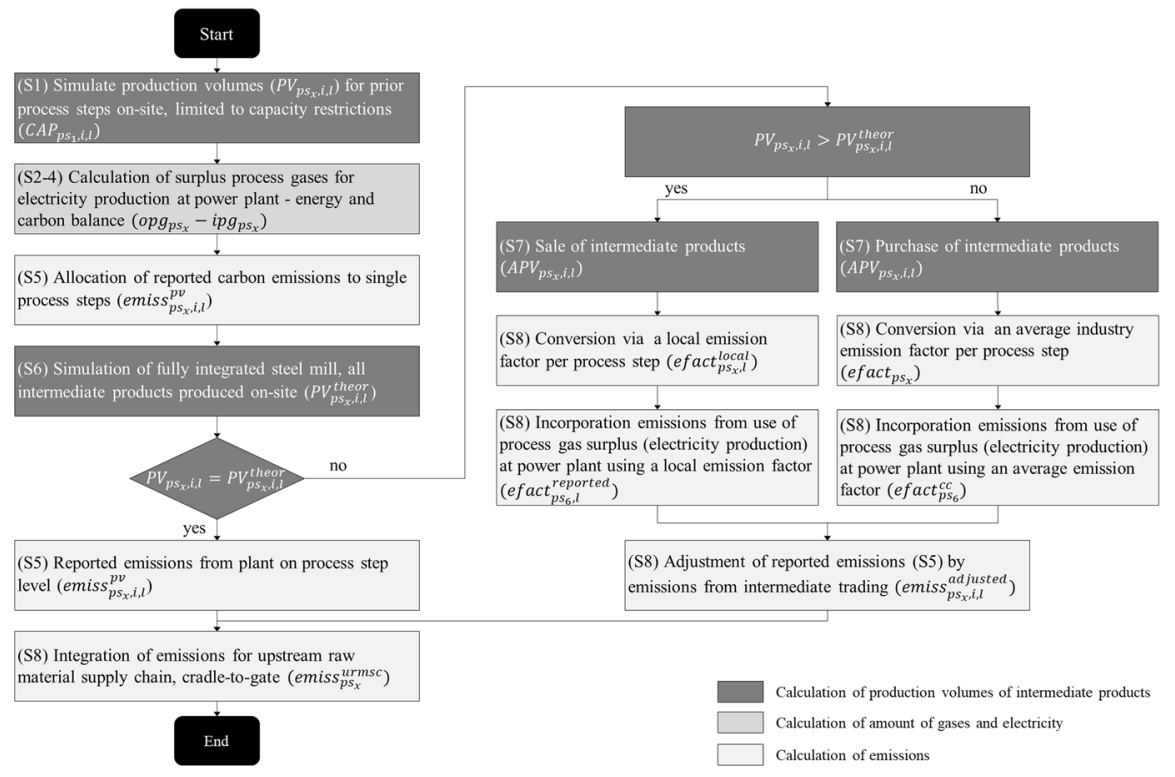

Fig. 6 Flow chart of the site-specific $\mathrm{CO}_{2} \mathrm{e}$ approach for predefined calculation steps. Note The single steps (S1-8) correspond to Sect. 4.3.2.5 and will be further explained in the text

The modular combination of a bottom-up and top-down LCA based approach is structured in eight steps (see Fig. 6). In Step 1 to Step 4 (S1-S4), the technologydriven bottom-up calculation of site-specific material and energy flows is described. In Step 5, the combination of the pre-results with the top-down, publicly available $\mathrm{CO}_{2}$ emissions per production location is completed. The modelling of fully integrated production plants is carried out in Step 6 and finalized with the credit calculation procedure for intermediate trading in Step 7 and Step 8. The analysis has revealed, that several facilities $(i)$ per process step $(x)$ at location $(l)$, may exist $\left(p s_{x, i, l}, x \in\{1 ; 6\}, i \in\{1, \ldots n\}, l \in\{1, \ldots m\}\right)$ and are therefore separately considered in the model. The production efficiency of each facility for one process step is assumed to be equal in the model. As the model development highly depends on the purpose of the study and the available data, the following modelling approach and the application of diverse structural data for the modelling phases are combined.

Step 1: Plant set-up to scale reported production volumes to process steps.

The examination of the plant set-up at the different production locations (see Table 3) aims at defining the basis for the later calculation of the internal material and energy flows and thus enables the determination of trading for intermediate products (exclusively within the boundaries of the European steel industry). The capacities for single process steps $\left(C A P_{p s_{x}, i, l}\right)$, published in the PLANTFACTS data base from the Association of German Steel manufacturers (VDEh 2014a), were used to determine if production for coke and sinter exist and is located on-site (see Table 3). The capacity restrictions for process steps which determine the external purchase or sale were also included in combination with the simulated production 
volumes. Steel manufacturers publish their production volumes on different levels of process steps $\left(P V_{p s_{x}, i, l}\right)$. The most detailed level of reporting includes the quantity of pig iron produced in the blast furnace $P V_{p s_{3}, i, l}$ (see Table 6). In this model, the reported production volume of the blast furnace at each examined location (see Sect. 4.3.2.2 and Fig. 5) was defined at this stage as a reference value for the definition of the amounts of intermediate products from upstream processes (coke oven $P V_{p s_{1}, i, l}$ and the sintering plant $\left.P V_{p s_{2}, i, l}\right)$. In order to simulate the overall production volumes including all process steps, average material conversion rates $\left(m c r_{p s_{x}, p s_{x}}\right)$ were utilized whenever the actual production volume of a prior process step is unknown:

$$
\begin{gathered}
P V_{p s_{1}, i, l}= \begin{cases}\left(m c r_{p s_{1}, p s_{3}}+m c r_{p s_{1}, p s_{2}} \times m c r_{p s_{2}, p s_{3}}\right) \times \sum_{\tilde{i}=1}^{\tilde{n}} P V_{p s_{3}, \tilde{i}, l} \times \frac{C A P_{p s_{1}, i, l}}{\sum_{\tilde{i}=1}^{n} C A P_{p s_{1}, \tilde{i}}}, & C A P_{p s_{1}, i, l}>0 \\
0, & C A P_{p s_{1}, i, l}=0\end{cases} \\
P V_{p s_{2}, i, l}= \begin{cases}m c r_{p s_{2}, p s_{3}} \times \sum_{\tilde{i}=1}^{\tilde{n}} P V_{p s_{3}, \tilde{i}, l} \times \frac{C A P_{p s_{1}, i, l}}{\sum_{\tilde{i}=1}^{\tilde{n}} C A P_{p s_{1}, \tilde{i}, l}}, C A P_{p s_{2}, i, l}>0 \\
0, & C A P_{p s_{2}, i, l}=0\end{cases}
\end{gathered}
$$

$\tilde{i}$ and $\tilde{n}$ serve as auxiliary variables and correspond to $i$ and $n$. The auxiliary variables are used throughout the further steps of calculation $\left(p s_{x, \tilde{i}, l}, \tilde{i} \in\{1, \ldots \tilde{n}\}\right)$. The calculation of the conversion rates (in $\left[\frac{t p s_{x}}{t p s_{x}}\right]$ ) relies on the upper and lower limits for single material and energy flows defined in the Best Available Techniques (BAT) documents, published by the European Commission (2013). It follows the approach presented by Breun (2016) based on a German industry average value for eight assessed integrated iron and steel mills:

$$
m c r_{p s_{1}, p s_{3}}=0.30, m c r_{p s_{1}, p s_{2}}=0.05, m c r_{p s_{2}, p s_{3}}=1.09, m c r_{p s_{3}, p s_{4}}=0.82 \text { and } m c r_{p s_{4}, p s_{5}}=1 \text {. }
$$

Company specific efficiency measures were neglected at this stage due to nonavailability of data, but are incorporated within the actually reported $\mathrm{CO}_{2}$ emissions in Step 5 and further discussed in the critical appraisal in Sect. 6. Downstream processes conducted in the basic oxygen furnace $\left(P V_{p s_{4}, i, l}\right)$ and the rolling plant $\left(P V_{p s_{5}, i, l}\right)$ were modelled according to the reported production volumes in proportion of the capacities of the single facilities $\left(C A P_{p s_{x}, i, l}\right)$ to the total capacity for each process step.

Step 2: Energy balance of process gases for reutilization on-site.

During the production of crude steel, several process gases such as coke oven gas (COG) (in $p s_{1}$ ) and blast furnace gas (BF gas) (in $p s_{3}$ ) are produced depending on the process depth located on the considered location. Also specific technologies which have a direct influence on the process gas flows, as for example basic oxygen furnace gas recovery $\left(B O G R_{l} \in\{1 ; 0\}\right.$, which leads to the availability of basic oxygen furnace gas (BOF gas) reuse (in $p s_{4}$ ), were explicitly incorporated. The reutilization of these gases, former waste products, as energy source during the production 
process is very common in the steel manufacturing process. In 2012, the share of self-produced electric power in Germany presented a share of $44 \%$ in comparison to the $56 \%$ share externally purchased electricity. Thus, steel manufacturers can reduce the dependency of external sources and operate more efficiently (VDEh 2013). The calculation was carried out by an input-output consideration of the process gases for each process step, depending of the plant setup and the existence of the process steps on-site. An energy balance was applied in order to determine a possible surplus of gases which is, in case of the installation of an on-site power plant, used for electricity production in $p s_{6}$. Therefore average amounts of energy $\left.\left(\left[\frac{\mathrm{MJ}}{\text { tintermediateproductps }}\right]\right]\right)$ per gas output at the origin of creation and gas input at the origin of reuse (see gas flows in Fig. 4) were applied according to the amount of actual intermediate products $\left(P V_{p s_{x}, i, l}\right)$ produced in the reference year (further calculations see Table 7).

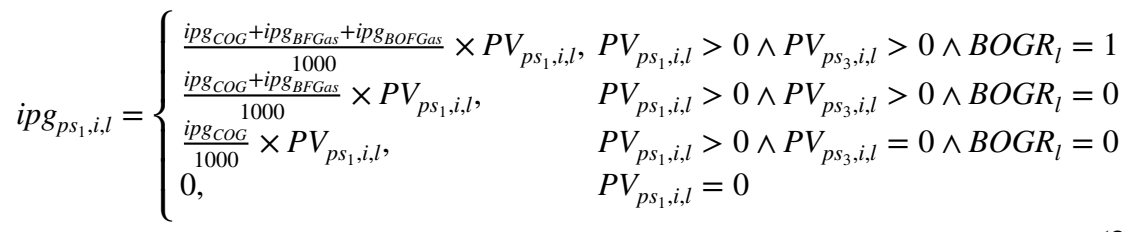

The values were derived from the NLP model for eight German production plants developed by Breun (2016) which are originally based on minimum and maximum values of the Best Available Techniques documents (European Commission, 2013) for Europe (see Table 8). A replacement of this data is possible if plant-specific primary data is available.

Step 3: Electricity production in connected power plants.

In this step, an estimation of electricity production was carried out, based on the energy balance and a calculated surplus of process gases. Additional secondary fuels for the power plant were included. Due to the scarce power plant data, no explicit amounts of secondary fuels could be determined. Furthermore, it was assumed that the electricity consumption remains constant over the years and that variations in a power plant specific energy balance are compensated by the addition of externally purchased natural gas. Subsequently, the ratio of an average factor for additional secondary fuels ( $s f f=1,68 \mathrm{GJ}$ ) per t crude steel (Breun 2016) in relation to a calculated average factor of electricity production per $t$ crude steel in Germany $($ aepg $=1,28 \mathrm{GJ})$ was applied on the plant-specific factor of electricity production per $t$ crude steel $\left(\right.$ power $\left._{p s_{6}, i, l}=\frac{p_{p o_{s s_{6}, i,} \times 3600 \times 24 \times 365 \times 50 \%}}{1000}\right)$. The site-specific power plant output $\left(\right.$ ppo $\left._{p s_{6}, i, l}\right)$ in MW per calendar year with an utilization rate of $50 \%$ was incorporated (see Table 3). With this approximation, power plant-specific average factors for additional secondary fuel (here: natural gas) were derived $\left(\right.$ ipg $_{N G, l}=\frac{s f f}{\text { aepg }} \times$ power $\left._{p s_{6}, i, l}\right)$. The model uses the amount of pig iron produced in the blast furnace $\left(p s_{4}\right)$ as reference value for the amount of required secondary fuels in the power plant. This simplification was assumed due to the high amount of surplus gases from the blast furnace, which are generally crucial for the operation of a 
power plant. Thus, the electricity production $\left(\right.$ elect $\left._{p s_{6}, i, l}\right)$ could be estimated by the utilization of an average electrical efficiency of $40 \%\left(e e_{p s_{6}}\right)$ dependent on the type of generator and the calorific value of the gas used. This value was obtained from the BAT document (European Commission 2013). With locally produced electricity, the dependence on external electricity supply can be reduced and furthermore electricity and heat can be sold to external parties.

$$
\begin{aligned}
\operatorname{elect}_{p s_{6}, i, l}= & \left(\sum_{\tilde{i}=1}^{\tilde{n}} \operatorname{spg}_{p s_{1}, p s_{3}, p s_{4}, \tilde{i}, l}-\sum_{\tilde{i}=1}^{\tilde{n}} i p g_{p s_{1}, p s_{2}, p s_{3}, p s_{4}, p s_{5}, \tilde{i}, l}\right) \\
& +i p g_{N G_{l}} \times \sum_{\tilde{i}=1}^{\tilde{n}} p v_{p s_{3}, \tilde{i}, l} \times e e_{p s_{6}} \times \frac{\operatorname{cap}_{p s_{6}, i}}{\sum_{\tilde{i}=1}^{\tilde{n}} c a p_{p s_{6}, \tilde{i}, l}}
\end{aligned}
$$

The estimated amount of produced electricity is also used to calculate emission factors (see Step 7) which are applied in the credit procedure. By putting the electricity amount (see Eq. (3)) in relation to the production volume of pig iron from the blast furnace $\left(P V_{p s_{5}, l}\right)$, the local electricity factor elect ${ }_{p s_{3, l}}^{l o c a l}$ and the average electricity factor elect $_{p s_{3}}^{\emptyset}\left(\left[\frac{\mathrm{GJ}}{\text { tintermediate productps }} s_{3}\right]\right)$ for the 22 examined plants were determined. In two cases, no power plant is installed and thus a surplus of gases is assumed to be flared. This leads to additional $\mathrm{CO}_{2}$ emissions without the possibility of energy recuperation.

Step 4: Carbon balance for process step specific carbon emissions.

According to the energy balancing in Step 2, a carbon balance was calculated to subsequently quantify the amount of carbon emissions from the power plant $\left(\right.$ emiss $\left._{f_{6}}\right)$.

$$
\begin{aligned}
\operatorname{emiss}_{p s_{6}, i, l}= & \frac{\left(\sum_{\tilde{i}=1}^{\tilde{n}} \operatorname{opg}_{p s_{1}, p s_{3}, p s_{4}, \tilde{i}, l}-\sum_{\tilde{i}=1}^{\tilde{n}} i p g_{p s_{1}, p s_{2}, p s_{3}, p s_{4}, p s_{5}, \tilde{i}, l}\right)+i p g_{N G_{l}} \times \sum_{\tilde{i}=1}^{\tilde{n}} p v_{p s_{3}, \tilde{i}, l} \times \frac{c c_{N G}}{1000}}{c c_{C O_{2}}} \\
& \times \frac{\operatorname{cap}_{p s_{6}, i, l}}{\sum_{\tilde{i}=1}^{\tilde{n}} c a p_{p s_{6}, \tilde{i}, l}}
\end{aligned}
$$

Therefore, initially the process gases were examined for its carbon content per energy (Pfeifer et al. 2009): coke oven gas 0.010 (kg C/MJ), blast furnace gas 0.071 ( $\mathrm{kg} \mathrm{C} / \mathrm{MJ})$, basic oxygen furnace gas $0.051(\mathrm{~kg} \mathrm{C} / \mathrm{MJ})$, natural gas 0.020 (kg C/MJ). In combination with the previously calculated average amounts of energy per gas output as well as gas input at the different process steps and a scaling to the actual amount of the according intermediate product produced onsite, a carbon balance could be quantified. Due to the utilization of secondary fuels for electricity production in the power plant, the carbon content of natural gas $\left(c c_{N G}\right)$ and the amount of produced pig iron as reference value needed to be included in the calculation. To estimate the carbon emissions of the power plant, an average factor for the carbon content of carbon dioxide $\left(\mathrm{cc}_{\mathrm{CO}_{2}}\right)$ of $0.3\left[\frac{\mathrm{kg} \mathrm{C}}{\mathrm{kg} \mathrm{CO}}\right]$ was consulted. 
Step 5: Allocation of reported carbon emissions to calculated carbon emissions.

In Step 1 to Step 4, the energy related $\mathrm{CO}_{2} \mathrm{e}$ emissions of the connected power plants (incl. secondary energy input) of specific production plants were estimated using a technology-driven bottom-up approach. Within Step 5, the actually reported $\mathrm{CO}_{2}$ emissions (emiss ${ }_{p s_{x}, i, l}^{\text {report }}$ ) on site level are integrated and constitute the basis for a following definition of local process related emission factors on a process steplevel. This enables the final emission adjustment for intercompany trading (see Table 10).

Taking a look at the reported site-specific $\mathrm{CO}_{2}$ emissions (top-down), usually a non-conformity of $\mathrm{CO}_{2}$ emission quantification becomes evident. Due to a missing standardization of the level of detail for the publication of plant-specific $\mathrm{CO}_{2}$ emissions, the granularity of data varies highly within the publications between a single $\mathrm{CO}_{2}$ emission value for the overall plant and seven single values for separate process steps. Thus, for an assignability to the according process steps, an intermediate calculation is necessary.

Similar to Step 1, the overall structure of the production plant was examined by the information obtained from the PLANTFACTS data base (VDEh 2014a) with respect to local process steps on site and number of facilities per process step (see Table 3). In an intermediate step, theoretical emissions $\left(\right.$ emiss $_{p s_{x}, i, l}^{\text {theor }}=e f a c t_{p s_{x}} \times P V_{p s_{x}, i, l}$ ) for each process step were calculated based on the production volumes defined in Step 1 by using average emission factors (see Table 9) derived from the BAT document (European Commission 2013). The reported emissions (European Environment Agency 2012) can now be physically allocated accordingly to the distribution of theoretical emissions for single process steps on a production site $\left(\right.$ emiss $_{p s_{x}, i, l}^{p v}=$ emiss $\left._{p s_{x}, i, l}^{\text {reported }} \times \frac{\text { emiss }_{p s_{x}, i, l}^{\text {ther }}}{\sum_{\tilde{x}=1}^{6} \text { emiss }_{p s_{x}, i, l}^{\text {ther }}}\right)$; $\tilde{x}$ serves as an auxiliary variable and corresponds to $x$. Thus, it is ensured that the calculated overall emissions correspond to the published emissions and that a plausible distribution on process step level is performed. For the power plant level, the same normalization was applied referring to the $\mathrm{CO}_{2}$ e emissions from the production of electricity, calculated in Step 4.

Step 6: Simulation of fully integrated steel mills to create a comparability

In terms of European emission reporting obligation, integrated iron and steel mills are defined as facilities which are located next to each other and functionally connected for the production of pig iron and further processing to crude steel. Preprocess steps for input materials such as coke and sinter are not yet separately considered in the reporting scheme (BMJV 2013). Thus, all required process steps for the production of crude steel are not necessarily carried out on-site. Furthermore, it is not assured that the amount of intermediate products produced onsite meets the necessary input amount for the down-stream process. Thus, trading of intermediate products results, and the reported $\mathrm{CO}_{2}$ emissions per site can consequently report too low (external procurement) or too high emission values (external sales).

To define the emissions for purchased or sold products, all 22 plants were modelled as fully integrated sites, meaning that all substantial intermediate 
products are simulated to be produced on site. The production volume of the basic oxygen furnace $\left(P V_{p s_{4}, i, l}=P V_{p s_{4}, i, l}^{\text {theor }}\right)$ was used as reference value to define the production volumes for the three upstream process steps. By means of material conversion rates (see Step 1) the production volumes for the process steps $p s_{1}, p s_{2}$ and $p s_{3}$ were simulated backwards. For example, the theoretical production volume $\left(P V_{p s_{x}, i, l}^{\text {theor }}\right)$ for the blast furnace, which is oriented by the following process step, is calculated as follows (further calculations see Table 11):

$$
P V_{p s_{3}, i, l}^{\text {theor }}= \begin{cases}\sum_{\tilde{i}=1}^{\tilde{n}} P V_{p s_{4}, \tilde{i}, l}^{\text {theor }} \times m c r_{p s_{3}, p s_{4}} \times \frac{C A P_{p s_{3}, i, l}}{\sum_{\tilde{i}=1}^{\tilde{n}} C A P_{p s_{3}, \tilde{i}}, l}, & C A P_{p s_{3}, i, l}>0 \\ \frac{\sum_{\tilde{i}=1}^{\tilde{n}} P V_{p s_{4}, \tilde{l}, l}^{\text {theor }} \times m r_{p s_{3}, p s_{4}}}{n}, & C A P_{p s_{3}, i, l}=0\end{cases}
$$

The downstream process in the rolling plant $\left(p s_{5}\right)$ equals the amount of production in the basic oxygen furnace (conversion rate of 1). This step creates the basis for a balancing of these differences in production volumes and resulting $\mathrm{CO}_{2} \mathrm{e}$ emissions by means of a following credit procedure (see Step 7).

Step 7: Credit procedure to integrate trading of intermediate products

Based on Step 1, the allocated actual production volumes $\left(P V_{p s_{x}, i, l}\right)$ on a process step level were set in relation with the theoretical volumes $\left(P V_{p s_{x}, i, l}^{\text {ther }}\right)$ in order to estimate additional production volumes which can be positive or negative: $A P V_{p s_{x}, i, l}=P V_{p s_{x}, i, l}-P V_{p s_{x}, i, l}^{\text {theor }}$. A negative $A P V_{p s_{x}, i, l}$ illustrates that the actual production volume does not meet the theoretical production volume and thus leads to a purchase of intermediate products in order to meet the actually produced amount of crude steel in the basic oxygen furnace. Correspondingly, the same applies for a positive additional production volume. The additional production volume is included in the emission adjustment (in Step 8).

However, not only the traded production volume is included but also energy amounts derived from the traded intermediate products have to be considered. Hence, according to Step 3, the amount of additional production volume from the blast furnace was referred to as a reference value. For purchased pig iron, an average electricity factor elect $_{p s_{3}}^{\emptyset}\left(\left[\frac{\text { GJ }}{\text { tintermediateproductps }_{3}}\right]\right)$ (see Step 3) was applied as the explicit origin of supply could not be predetermined in the model. In the opposite case, the local estimated electricity factor elect ${ }_{p s_{3}, i, l}^{\text {local }}\left(\left[\frac{\mathrm{GJ}}{\text { tintermediateproductps }_{3}}\right]\right)$ was utilized:

$$
A P V_{p s_{6, i, l}}= \begin{cases}\sum_{\tilde{i}=1}^{\tilde{n}} A P V_{p s_{3}, \tilde{i}, l} \times \text { elect }_{p s_{3}, i, l}^{l o c a l}, & A P V_{p s_{6}, i, l}>0 \\ \sum_{\tilde{n}}^{n} A P V_{p s_{3}, \tilde{i}, l} \times \text { elect }_{p s_{3},}^{\infty}, & A P V_{p s_{6}, i, l}<0 \\ 0, & A P V_{p s_{6}, i, l}=0\end{cases}
$$

Step 8: Emission adjustment to combine the reported and calculated emissions.

Based on the previous calculation steps, the plant-specific estimation of $\mathrm{CO}_{2} \mathrm{e}$ emissions, referred to the functional unit, can be computed. Besides the amount of 
electricity produced in the power plant, the trading of intermediate products has a direct influence on the $\mathrm{CO}_{2}$ e balance of the examined process steps and thus on the overall plant emissions. By means of emission factors, the emissions resulting from the trading were defined (emiss $p_{p s_{x}, i, l}^{a p v}$ ) on a process step level:

$$
\text { emiss }_{p s_{x}, i, l}^{a p v}= \begin{cases}A P V_{p s_{x}, i, l} \times e^{2 a c t}{ }_{p s_{x}, i, l}^{\text {local }}, & A P V_{p s_{x}, i, l}>0 \\ A P V_{p s_{x}, i, l} \times e f a c t_{p s_{x}, i}, & A P V_{p s_{x}, i, l}<0 \\ 0 & A P V_{p s_{x}, i, l}=0\end{cases}
$$

Purchased products which could not be traced back, were adjusted via an average industry factor efact $_{p s_{x}}$ (European Commission 2013). On the other hand, resulting from Step 5, a local factor for sold products was applied. Therefore, the reported emissions which were allocated to the single process steps were put in relation to the actual production volumes $\left(e f a c t_{p s_{x}, i, l}^{l o c a l}=\frac{e m i s s_{p s_{x}, i, l}^{p v}}{P V_{p s_{x}, i, l}}\right)$. A particular focus was again set on the power plant as a sink for the management of internal energy flows from the process gases. For the credit procedure of the power plant (see Eq. (8)), the overall amount of produced electricity was credited at first, by means of an average emission factor efact ${ }_{p s_{6}}^{\text {electmix }}$ (see Table 12) depending on the country where the manufacturer is located (Ecoinvent 2007-2013; UBA 2012). Then, corresponding to the previous calculation, a distinction between the traded products and its emission factor had to be made. Thus, an average factor efact ${ }_{p s_{6}}^{c c}$ of all 22 investigated plants was calculated from the carbon balance in Step 4 in relation to the locally produced amount of electricity. It served to adjusting the externally sourced products, whereas sold products were adjusted by a plant-specific emission factor efact ${ }_{p s_{6}, l}^{\text {reported }}$ that was derived from the $\mathrm{CO}_{2} \mathrm{e}$ emissions which were allocated to the power plant in combination with the locally produced electricity.

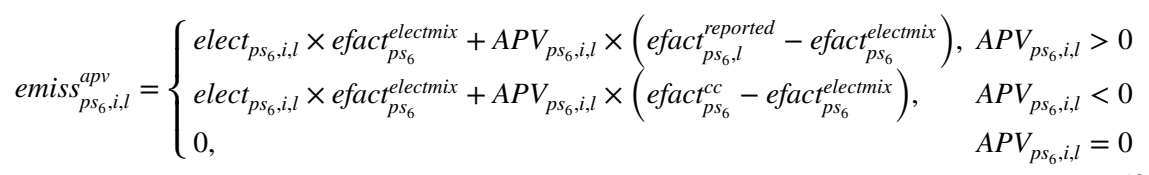

In order to reach the targeted comparability, the reported $\mathrm{CO}_{2}$ emissions from production sites and the extended adjusted emissions due to the intermediate trading were summed up to emiss ${ }_{p s_{x}, i, l}^{\text {adjusted }}$.

$$
\sum_{i=1}^{n} \text { emiss }_{p s_{x}, i, l}^{\text {adjusted }}=\sum_{i=1}^{n} \operatorname{emiss}_{p s_{x}, i, l}^{p v}+\sum_{i=1}^{n} \operatorname{emiss}_{p s_{x}, i, l}^{a p v}
$$

The values were conclusively standardized to the amount of crude steel in order to meet the primarily defined functional unit $\mathrm{kg} \mathrm{CO}_{2} \mathrm{e} / \mathrm{t}$ crude steel.

Finally, industry average $\mathrm{CO}_{2} \mathrm{e}$ emission values derived from the ecoinvent data base (Ecoinvent 2007-2013) for the upstream raw material supply chain, 
cradle-to-gate, were integrated depending on the necessary production volumes $P V_{p s_{x}, i, l}^{\text {theor }}$ (see Step 6).

$$
\text { emiss }_{p s_{x}, i, l}^{\text {urmsc }}=e f a c t_{p s_{x}}^{\text {urmsc }} \times 1000 \times \sum_{\tilde{i}=1}^{\tilde{n}} P V_{p s_{x}, \tilde{i}, l}^{\text {theor }}
$$

Due to the missing data availability regarding the exact energy balance for single process steps, average input for electricity and natural gas was used for all process steps in the production plant. As electricity plays a major role being one of the top three triggers for $\mathrm{CO}_{2} \mathrm{e}$ emissions in the upstream supply chain, the carbon footprint for the electricity input at the different process steps was adjusted on a regionalcountry-basis (see Table 12). On country level, the country specific data for conversion rates of the energy mixes to $\mathrm{CO}_{2} \mathrm{e}$ are available (see Sect. 4.3.2.4 and Table 12). For the power plant $\left(p s_{6}\right)$ the amount of produced electricity was consulted.

$$
\text { emiss }_{p s_{6}, l}^{u r m s c}=\frac{\sum_{i=1}^{n} e^{e l e c t_{p s_{6}, l}}}{e e_{p s_{6}}} \times 1000 \times e f a c t_{p s_{6}}^{u r m s c}
$$

The secondary fuel natural gas has already been used in several steps of the calculation. As illustrated in Eq. (8) the overall amount of electricity which includes the addition of natural gas in the power plant has been credited and then adjusted by the amount of products traded. However, the actual $\mathrm{CO}_{2} \mathrm{e}$ emissions for the externally purchased natural gas for the power plant $\left(i p g_{N G}\right)$ have not been included yet. These are calculated with average values (efact ${ }_{p s_{6}}^{u r r s, N G}$ ) from (Ecoinvent 2007-2013), scaled to the power plant-specific average factors for additional secondary fuel (see Step 3), and the theoretical production volume of the blast furnace at the considered plant.

$$
\operatorname{emiss}_{p s_{6}, l}^{\text {urmsc,NG}}=\sum_{i=1}^{n} P V_{p s_{3}, i, l}^{\text {theor }} \times i p g_{N G_{l}} \times e f a c t_{p s_{6}}^{u r m s c, N G}
$$

\section{Combination of sub-models and application on automotive case study}

\subsection{Results of the site-specific $\mathrm{CO}_{2}$ e model applied on EU-15 steel manufacturers}

The model was applied on the EU-15 integrated steel plants (22 locations) which have a maximum of four facilities $(i)$ per process step $(x)$ at location $(l)$ $\left(p s_{x, i, l}, x \in\{1 ; 6\}, i \in\{1 ; 4\}, l \in\{1 ; 22\}\right)$. The results of the estimation (see Fig. 7) clearly show wide differences among the steel mills under study. This confirms the initially described need for a site-specific assessment of suppliers $\mathrm{CO}_{2}$ e performance (see Sect. 4.2.3), when $\mathrm{CO}_{2} \mathrm{e}$ shall be used for making supplier selection decisions. The estimated overall amounts for fully integrated steel mills in $\mathrm{kg} \mathrm{CO}_{2} \mathrm{e} / \mathrm{t}$ crude 


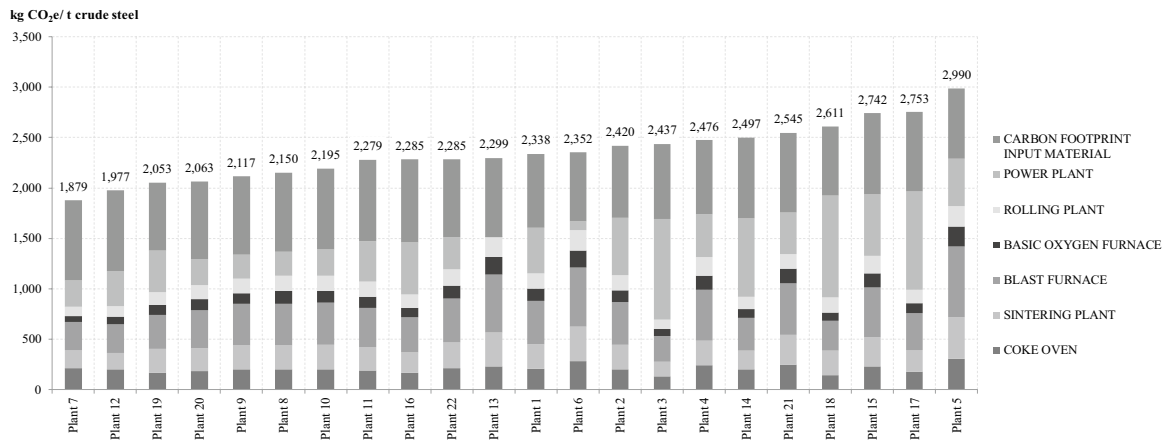

Fig. 7 Results of the 22 integrated steel mills in EU-15 after the emission adjustment

steel (see Sect. 4.3.2.5) range from "Best-in-Class" (BiC) $1879 \mathrm{~kg} \mathrm{CO}_{2} \mathrm{e} / \mathrm{t}$ crude steel to "Worst-in-Class" (WiC) $2990 \mathrm{~kg} \mathrm{CO}_{2} \mathrm{e} / \mathrm{t}$ crude steel and illustrate a deviation of 58\%. On average, $2352 \mathrm{~kg} \mathrm{CO} 2 \mathrm{e} / \mathrm{t}$ crude steel are emitted among the investigated steel plants. The differences of the estimated manufacturer's performances can be traced back to several reasons. One significant reason is that not all plants are fully integrated, meaning that some necessary process steps are not located at site and thus the according intermediate products need to be purchased externally. This can have a negative effect as for example the reuse of process gas flows and the internal energy management are not linked as efficiently as possible in comparison to fully integrated plants. Variations in capacity utilization rate additionally reinforce this argument. Moreover, company internal process know-how on efficiency measures and process step specific adjustments of technological installations play an important role. The country specific energy mix depending on the location of the manufacturing plant can also affect the results, as the avoidance of external electricity generation is credited in the model. Due to the top-down integration of the reported $\mathrm{CO}_{2} \mathrm{e}$ emissions and the further conducted allocation of the process steps, the values for the single production steps do show discrepancies. However, all reported $\mathrm{CO}_{2}$ emissions were incorporated and the overall value per production plant (see Fig. 7) is oriented to the main production volumes and the according emissions.

In an exemplary application, the results obtained from the developed site-specific, attributional approach were used to derive consequences for the overall amount of emissions in Europe. A projection of all new registered 14,648 Mio cars in Europe in 2015 [share of $912 \mathrm{~kg}$ steel from a VW GOLF VII (Lieberwirth and Krampitz 2015)] with the estimated average environmental impact from the examined steel manufacturers $2353 \mathrm{~kg} \mathrm{CO}$ e/t crude steel, illustrates a 1\% share of the overall European GHG emissions. Thus, a comparison of the $\mathrm{BiC}$ and $\mathrm{WiC}$ steel supplier in terms of environmental impact, calculated with the same parameters as above, shows an annual reduction potential of $15 \mathrm{Mt} \mathrm{CO}_{2} \mathrm{e}$ with respect to all newly registered cars in Europe, here calculated for 2015. It confirms the necessity of a sitespecific consideration and more generally the need to foster technological improvements of steel manufacturers from a sustainable perspective. As currently not all customers can possibly source the material from the BiC supplier due to capacity 
restrictions, it represents only an individual perspective. However, a rising demand for 'greener' produced steel from several customers will urge supplier to rethink existing processes in order to maintain competitive advantages and market share. In addition, it will in consequence, create a movement of the entire steel producing market in terms of reducing the carbon footprint of steel products. Moreover, if a carbon neutrality is pursued, as illustrated by the Volkswagen ID project in Sect. 1, even the most efficient, $\mathrm{BiC}$ supplier will be obliged to further develop new production technologies and continue to maximize efficiency in production processes.

\subsection{Validation of the $\mathrm{CO}_{2} \mathrm{e}$ assessment model}

A validation with the primary data of three out of the 22 manufacturers was carried out. Over a period of 2 years, each step of the calculation, the described assumptions as well as the logic for creating a comparability by simulating fully integrated plants (each process step on-site) were analyzed. This was carried out in depth and validated with one manufacturer from the German-speaking region. The modeled trading of intermediate products at various process steps was confirmed while no confidential company internal know-how was disclosed. Due to confidentiality reasons, only variances in percent of the overall plant value $\left(\mathrm{kg} \mathrm{CO}_{2} \mathrm{e} / \mathrm{t}\right.$ crude steel) can be published but these illustrate an auspicious deviation of max. 5\%. Moreover, the estimated average of $2352 \mathrm{~kg} \mathrm{CO}_{2} \mathrm{e} / \mathrm{t}$ crude steel goes coherently with the consulted ecoinvent average values for Europe-2408 $\mathrm{kg} \mathrm{CO}_{2} \mathrm{e} / \mathrm{t}$ crude steel (Ecoinvent 2007-2013) and show only a deviation of $2.3 \%$.

\subsection{Integration of site-specific $\mathrm{CO}_{2}$ e emissions into the decision support model}

As initially described, an integration of $\mathrm{CO}_{2} \mathrm{e}$ as decision criteria was not possible as only average values were accessible and these do not allow for a site-specific consideration, which is necessary for making a supplier selection. With the developed sitespecific $\mathrm{CO}_{2} \mathrm{e}$ approach this hurdle can be overcome. Thus, similar to first application in Sect. 4.2.3, now the results for the EU-15 steel manufacturers are integrated in the supplier selection model and a ranking is derived. The same sample part with a total weight of $18.36 \mathrm{~kg}$, which was again assumed to be produced exclusively from crude steel using, was used, however the $\mathrm{CO}_{2}$ e performance varies due to now consulted site-specific values per t crude steel (see Fig. 8, case 3). The supplier specific values lead to a total $\mathrm{CO}_{2} \mathrm{e}$ performance of $50.53 \mathrm{~kg} \mathrm{CO} 2 \mathrm{e} /$ part for supplier 1 (by $2753 \mathrm{~kg} \mathrm{CO} \mathrm{Ka}_{2} \mathrm{e} / \mathrm{t}$ crude steel), of $43.17 \mathrm{~kg} \mathrm{CO} \mathrm{C}_{2} \mathrm{e} /$ part for supplier 2 (by $2352 \mathrm{~kg}$ $\mathrm{CO}_{2} \mathrm{e} / \mathrm{t}$ crude steel), of $37.68 \mathrm{~kg} \mathrm{CO} \mathrm{e} /$ part for supplier 3 (by $2053 \mathrm{~kg} \mathrm{CO}_{2} \mathrm{e} / \mathrm{t}$ crude steel), of $43.17 \mathrm{~kg} \mathrm{CO}_{2} \mathrm{e} /$ part for supplier 4 (by $2352 \mathrm{~kg} \mathrm{CO}_{2} \mathrm{e} / \mathrm{t}$ crude steel) and of $42.92 \mathrm{~kg} \mathrm{CO}_{2} \mathrm{e} /$ part for supplier 5 (by $2338 \mathrm{~kg} \mathrm{CO}_{2} \mathrm{e} / \mathrm{t}$ crude steel). The supplier specific performance scores, which are now integrated into the sub-model for decision support based on the investigated criteria weight of $2.67 \%$, lead to a new supplier ranking of S3 $\rightarrow \mathrm{S} 1 \rightarrow \mathrm{S} 2 \rightarrow \mathrm{S} 5 \rightarrow \mathrm{S} 4$. The deviation of environmental performance score of $34.10 \%$ for supplier 1 and 3 in case 3 leads to a different decision, preferring supplier 3 over supplier 1 . Hence, the initially described necessity of 


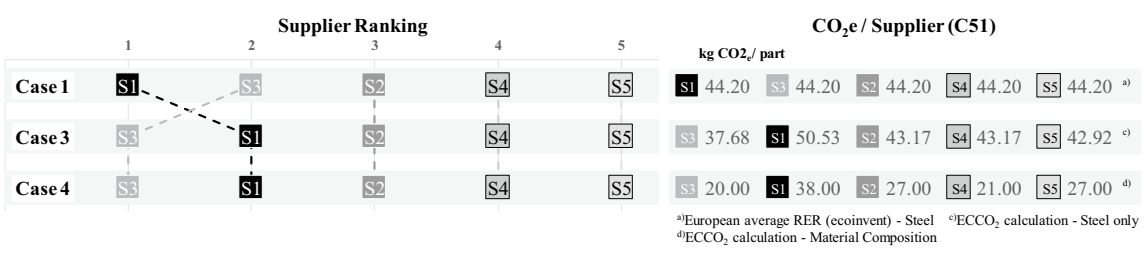

Fig. 8 Influence of $\mathrm{CO}_{2} \mathrm{e}$ (C51) on supplier ranking (part 2)

site-specific $\mathrm{CO}_{2} \mathrm{e}$ performance values as basis for the integration of $\mathrm{CO}_{2} \mathrm{e}$ as criteria for supplier selection is considered to be confirmed.

After the general confirmation of the functionality of the model, from this point onwards, a more complex material composition of the sample part was applied, which represents a real-life case of a part sourced by a German OEM from a Tier-1 supplier. This was chosen to demonstrate the possibility of the model to include different materials in the decision-making process in combination with site-specific $\mathrm{CO}_{2}$ e performances. The part, with the same total weight of $18.36 \mathrm{~kg}$, consists of various components (see Table 5) made by primary and secondary steel as well as aluminum, plastics (Polyamide 6) and a small share of additional materials (the calculation of aluminum and plastics, which follow the principles of the site-specific $\mathrm{CO}_{2} \mathrm{e}$ model, are currently not yet published). The consideration of the real life case for a part (see Fig. 8, case 4), consisting of diverse raw materials, shows the following $\mathrm{CO}_{2} \mathrm{e}$ performance scores: $38 \mathrm{~kg} \mathrm{CO}$ e/part for supplier $1,27 \mathrm{~kg} \mathrm{CO}_{2} \mathrm{e} /$ part for supplier 2, $20 \mathrm{~kg} \mathrm{CO}_{2} \mathrm{e} /$ part for supplier 3, $21 \mathrm{~kg} \mathrm{CO}_{2} \mathrm{e} /$ part for supplier 4, and $27 \mathrm{~kg}$ $\mathrm{CO}_{2} \mathrm{e} /$ part for supplier 5 .

The emissions for further processing and logistics, as described in Sect. 4.2.3, were excluded and the focus was laid on the $\mathrm{CO}_{2}$ e emission from raw materials used in the selected part. The different $\mathrm{CO}_{2}$ e performance scores per part can be attributed on the one hand to the site-specific efficiencies from the raw material suppliers, as illustrated in Sect. 5.1 for primary steel and on the other hand, to slight variations in the material composition of the raw material used. For example, primary aluminum has a very high $\mathrm{CO}_{2}$ e performance score per $\mathrm{t}$ compared to steel, due to the strong dependency on electricity and thus the country specific energy mix. Due to confidentiality no further breakdown of the percent share of material could be published. The application of the real-life case, which shows a changed ranking with $\mathrm{S} 3$ as preferred supplier, $\mathrm{S} 3 \rightarrow \mathrm{S} 1 \rightarrow \mathrm{S} 2 \rightarrow \mathrm{S} 5 \rightarrow \mathrm{S} 4$, finally confirms the necessity and general functionality of the model.

\subsection{Sensitivity analysis}

A sensitivity analysis was performed to further analyze the stability of the results from the pairwise comparison and thus test the robustness of the model. This shall help decision makers to identify most critical pairwise comparisons and to derive, if necessary, adjustments in selection criteria. By means of a numerical incremental 


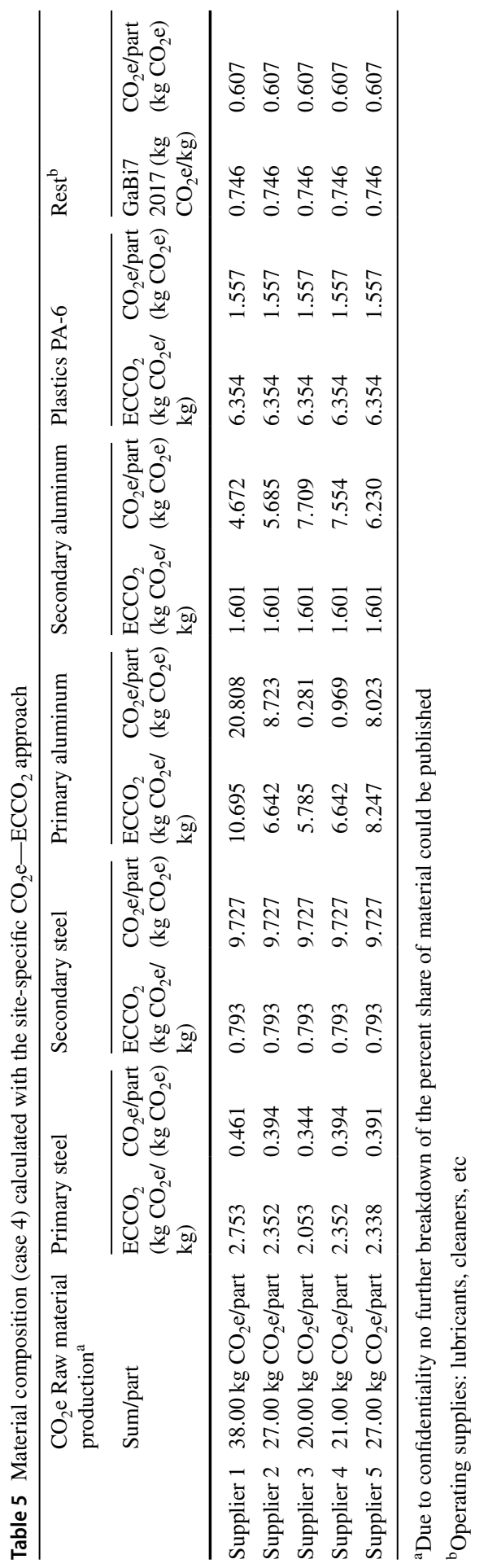



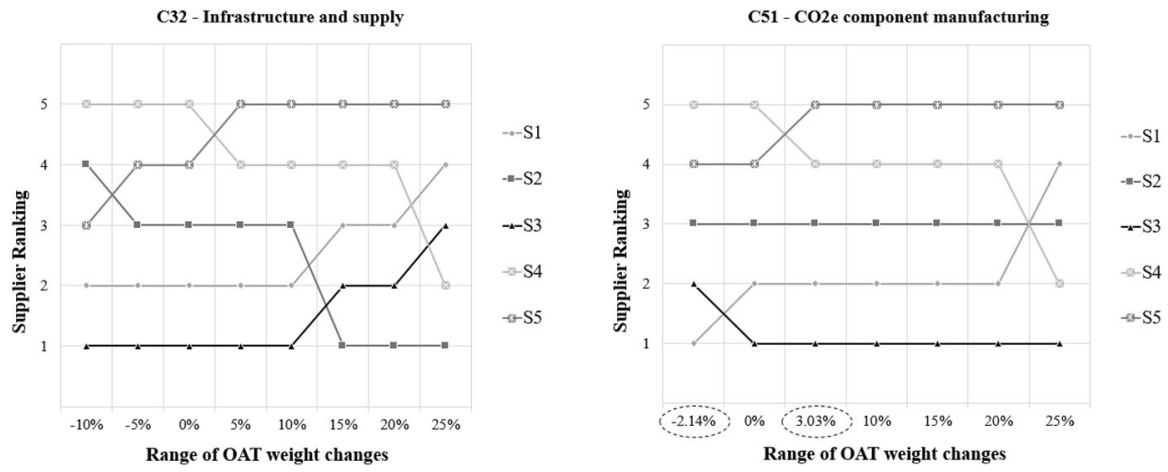

Fig. 9 Effects of the sensitivity analyses under different criteria weights (OAT)

analysis, the criteria weights were constantly changed one-at-a-time (OAT) in steps of $\pm 5 \%$ up to $\pm 25 \%$ (Leonelli 2012) and the ranking results were analyzed. The OAT was carried out based on the derived criteria weights (see section Table 1) and was applied on the real-life case study part (see Table 2), including the supplier specific $\mathrm{CO}_{2} \mathrm{e}$ performance scores in case 4 , which were derived from the site-specific $\mathrm{CO}_{2}$ e model (see Table 5).

The results show an overall robustness for all criteria of $95 \%$ in terms of first ranked supplier, 94\% of first and second ranked supplier and $91 \%$ of the first three rankings. It illustrates that the proposed decision-making process including $\mathrm{CO}_{2} \mathrm{e}$ as new criteria is relatively insensitive to criteria weighting. The examination of the single criteria conducted in this matter identifies "Infrastructure and supply" as subcriteria of the local criteria "Flexibility" (see Tables 1, 2) as the most critical criteria. It shows a robustness of $57 \%$ for the first ranked supplier, $57 \%$ for the first and second ranked supplier and $52 \%$ of the first three rankings. The results, illustrated in Fig. 9, may lead to a re-evaluation of the necessity of this criteria by the decision maker.

In Fox et al. (2015), a course of action is explained whether the criteria shall remain for the decision process. Accordingly, the purchasing experts were re-consulted and the necessity of the criteria was confirmed. The pairwise comparisons were then critically reviewed in order to ensure that the results represent the decision maker's preferences (see Table 1) and were presented to the purchasing experts. Consequently, a strong focus needs to be laid upon data gathering and accuracy of results when the decision criteria is used (Fox et al. 2015). Based on the goal of the study to integrate $\mathrm{CO}_{2} \mathrm{e}$ from the manufacturing phase into supplier selection decisions, a special focus was laid upon the sensitivity analysis for the new criteria. A robustness of $100 \%$ for the first ranked supplier, $90 \%$ for the first and second ranked suppliers and $93 \%$ for the ranking of the first three suppliers is derived from the oneat-a-time sensitivity method, if the criteria weight is increased.

However, a more in-depth examination (see Fig. 9) of each single criteria reveals that a reduction of only $2.14 \%$, resulting in a weight of $0.53 \%$, has a strong impact on the ranking and causes a switch of the top two ranked suppliers and makes C51 
the Absolut-Top (AT) critical criteria (Triantaphyllou and Sánchez, 1997). In addition, C51 also represents the Absolut-Any (AA) critical criteria, meaning that the smallest change among all criteria, leads to any change in the ranking. The analysis shows that the increase of $3.03 \%$ already triggers a switch of the 4th and 5 th ranked suppliers (see Fig. 9). Equally to the proposed treatment of criterion C32, the integration of $\mathrm{C} 51$ requires an even stronger focus on data collection and precision for decision makers. As the expert interviews revealed that $\mathrm{CO}_{2} \mathrm{e}$ is basically not of importance for the current decision-making process, the results of the sensitivity analysis highlight even more that not only the introduction of $\mathrm{CO}_{2} \mathrm{e}$ as new criteria is important. Also the integration in form of weighting assignment requires a thorough procedure. Finally, the rank reversal issue was tested by adding another sixth alternative/supplier (copy of the last ranked supplier performance) and deleting one alternative (Fox et al. 2015). The results show no changes in the ranking further contributing to the general robustness of the model.

\subsection{Scenario simulation to support the formulation of $\mathrm{CO}_{2} \mathrm{e}$ as decision criteria}

At this point the created $\mathrm{CO}_{2}$ e performance scores of suppliers, exclusively for cradle-to-gate raw material production, were used to simulate different future scenarios from an environmental and economic perspective.

One way of scenario simulation could be the integration of $\mathrm{CO}_{2} \mathrm{e}$ performances directly into the existing cost criterion $\mathrm{C} 11$. Based on the expert interviews, from a corporate perspective, this would be the most preferable solution in order to establish a consistent application of the $\mathrm{CO}_{2} \mathrm{e}$ criteria in decision making processes. As the European Commission (EPSC 2016) has started first discussions on possibly regulating $\mathrm{CO}_{2}$ e from the manufacturing phase in the future, a simulation was carried out assuming a $\mathrm{CO}_{2} \mathrm{e}$ limit in combination with a monetary penalty for the exceeding of the limit, similar to the principle of regulating $\mathrm{CO}_{2}$ emissions in the use-phase. The objective pursued was to investigate how these assumptions might affect current supplier selection decisions. The currently separate criteria weight for $\mathrm{CO}_{2} \mathrm{e}$ was proportionally distributed among the other criteria. This assumption was justified with the initially investigated zero importance of $\mathrm{CO}_{2}$ e from manufacturing during the expert interviews (see Sect. 4.2.2). The adjusted criteria weights without the $\mathrm{CO}_{2}$ e criteria can be found in Table 1. The application of these weights results in the following supplier ranking: $\mathrm{S} 1 \rightarrow \mathrm{S} 3 \rightarrow \mathrm{S} 2 \rightarrow \mathrm{S} 5 \rightarrow \mathrm{S} 4$.

A penalty of $80.00 € / \mathrm{tCO}_{2} \mathrm{e}$ corresponding to the cost approach from the German Federal Environment Agency for $\mathrm{CO}_{2}$ relation to climate damage (UBA 2014) was assumed. Now the performance score of the currently selected supplier $\mathrm{S} 1,38 \mathrm{~kg}$ $\mathrm{CO}_{2} \mathrm{e}$ /part was used as basis for simulating possible $\mathrm{CO}_{2} \mathrm{e}$ reduction targets. This procedure follows the principles of sensitivity analysis for investigating the most critical measure of performance (Triantaphyllou and Sánchez 1997). The simulation analysis shows that the setting of a $\mathrm{CO}_{2} \mathrm{e}$ limit per part of $20.60 \mathrm{~kg} \mathrm{CO}_{2} \mathrm{e} /$ part, which represents a reduction of $45.80 \%$ of the performance of the currently selected supplier 1, leads to a first change of the supplier ranking: S3 $\rightarrow \mathrm{S} 1 \rightarrow \mathrm{S} 2 \rightarrow \mathrm{S} 5 \rightarrow \mathrm{S} 4$. 


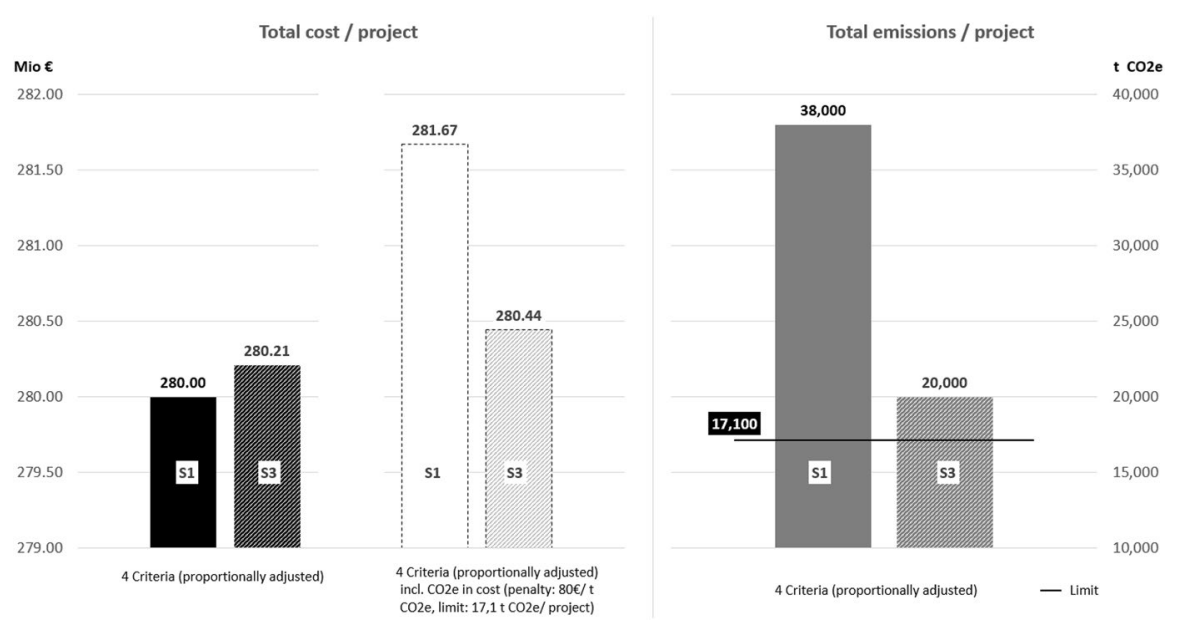

Fig. 10 Illustration of results of a simulation of environmental and economic effects

As the environmental performance of S3 lies below the introduced limit, no penalties have to be considered. In order to better demonstrate the idea of the simulation procedure, a limit of $17.10 \mathrm{~kg} \mathrm{CO} \mathrm{CO}_{2} \mathrm{e}$ part, representing a reduction of $55.00 \%$, was used for the subsequent simulation. Before the integration of the $\mathrm{CO}_{2}$ e performance into the cost criteria with the assumed penalty and limit, the overall project cost of the selected supplier S1 would be 280.00 Mio $€$. This corresponds to emitting $38,000 \mathrm{t} \mathrm{CO}_{2} \mathrm{e}$ over the project duration. Supplier S3 would be ranked second with overall project cost of 280.21 Mio $€$ while emitting only 20,000 t $\mathrm{CO}_{2} \mathrm{e}$. After the introduction of the $\mathrm{CO}_{2}$ e criteria the ranking changes and supplier S3 would become the best ranked alternative by $280.44 \mathrm{Mio} €$ by a remaining $\mathrm{CO}_{2} \mathrm{e}$ performance (see Fig. 10). Supplier S1 would now be ranked second due to overall project cost of 281.67 resulting from its higher emission of $\mathrm{CO}_{2} \mathrm{e}$. Even though supplier S3 would initially represent slightly higher project cost of 0.210 Mio $€$ and would also have to pay a penalty of 0.232 Mio $€$, its selection would result in a reduction of 18,000 t $\mathrm{CO}_{2} \mathrm{e}$, and an avoidance of 1.230 Mio $€$ additional cost. The illustrated example shall serve to demonstrate how a variety of future scenarios (economic and environmental) can be modelled in order to formulate the specification of a new selection criteria, as in this case $\mathrm{CO}_{2} \mathrm{e}$ and derive sustainable supplier selection strategies.

\section{Conclusion and outlook}

Given the overriding goal to limit global warming, further accompanying fields of research are gaining importance. The manufacturing of passenger vehicles might constitute one out of many areas which could contribute to the set environmental goals.

As mentioned previously, the public availability of primary data is currently restricted and does thus not allow a decision to be made on a site-specific level. 


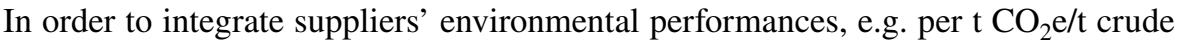
steel, into supplier selection, industry averages do not present the necessary data granularity. The proposed approach overcomes this hurdle by putting the focus on extending the commonly used bottom-up LCA method with the top-down integration of reported company specific emissions. By this means, company specific process improvement measures, which outline the core competences of the suppliers and might vary not only between companies but also between production sites, are included (see Sect. 4.3.2.5, Step 6). Hence, the missing availability of data is overcome and the complexity regarding the level of process depth is efficiently limited to the necessary maximum. The developed model presents a possible approach to estimate site-specific $\mathrm{CO}_{2} \mathrm{e}$ emissions in order to create comparability between steel manufacturers' production sites and thus enables an integration into supplier selection. Due to the created transparency and comparability, the developed methodology aims at contributing to the scientific field of sustainability management. This illustrates a step forward as to enable an integration of $\mathrm{CO}_{2} \mathrm{e}$ performances as decision criteria in the supplier selection process. In terms of the practical application of this model and the refinement of the estimation, it is possible to easily integrate updated data of future reference years, changes in the steel industry as well as site-specific primary data when available.

The results show that the integration of $\mathrm{CO}_{2} \mathrm{e}$ as decision criteria, based on a sitespecific supplier performance assessment, can support the supplier selection process in order to significantly reduce $\mathrm{CO}_{2} \mathrm{e}$ emissions. Furthermore, the proposed AHP/ TOPSIS model combined with a sensitivity analysis and scenario simulation can assist decision makers with the formulation of the new criteria in order to improve sustainable efficiencies of products while considering the economic effects. In the field of multi-criteria decision making, the application of other ranking as well as sensitivity methods, such as probabilistic simulations, or mathematical models, could be promising in order to investigate reproducibility of results. Moreover, other selection criteria could be consulted in order to further examine effects on sensitivity of the new $\mathrm{CO}_{2} \mathrm{e}$ criteria. Further emphasize on the illustrated scenario modelling on economic effects could illustrate a promising field for future research. Different cost rates, e.g. derived from the German vehicle taxation model (Gawel 2011) or the European trading scheme for carbon dioxide (UBA 2018b), could be analyzed in the developed approach. In combination, research on the definition of emission limits relating to the defined environmental goals could be extended. Interesting approaches regarding the reduction of $\mathrm{CO}_{2} \mathrm{e}$ could be the European regulations on vehicle usage, fleet targets for vehicle manufacturers (European Commission 2009), or the sectoral decarbonization approach, a method for companies to set emission targets contributing to the two degrees goal (Science Based Targets Initiative 2015). In order to derive even more universal conclusions, the model should be applied to a broader scope of parts from a company. Additionally, the principle of sensitivity analysis could be applied while the ratio of economic and environmental performance is investigated. It could be used to derive a certain monetary value for $\mathrm{CO}_{2} \mathrm{e}$ from the perspective of the decision maker and for new strategic alignments in supplier selection processes. An application extension of the estimated site-specific 
emissions to supplier development and monitoring could furthermore illustrate an interesting field for scientific research.

However, some existing limitations could be investigated in future research. For missing actual production volumes of process steps such as coke production, a calculation was carried out (see Sect. 4.3.2.5, Step 1). Due to the unavailability of data, the approach assumed the production volume of the blast furnace as basis for the calculation of upstream process steps. Some manufacturers could produce more coke than needed for the on-site pig iron production for market sales. At this point site-specific primary information could be integrated, if available. To create comparability, the alloying process was neglected as the composition of the alloys highly depend on customer-specific requirements and do not influence the energy management system of a production plant. However, the according data could be integrated accordingly to the addition of the carbon footprint of raw materials in Step 8. The carbon footprint for raw and all other necessary input materials was included by the use of average data from an industry data base. Future research on the transparency of upstream supply chain material production on site-specific level could illustrate an interesting topic to increase the accuracy over the whole supply chain. The presented approach primarily focused on the environmental performances in the focus system "Production Plant". However special attention was placed upon the internal process gas flows reutilization, either as energy carrier for other process steps directly or a surplus of gases for electricity generation in a connected power plant. A future extension of the focus system towards inter-industrial trading of by-products respectively residues and a resulting credit procedure for the avoidance of emissions could be of interest. Production residues comprise, among others slags, dust, sulphur or sulphuric acid, ammonium sulphate, benzene, coke tar and coke pitch (European Commission 2013). The reuse of steel and blast furnace slag in cement production or of process gases in the chemical industry, as for example described in the "carbon2chem" initiative (Thyssenkrupp 2018) could be investigated. Furthermore, the scope of the research on supply chain transparency should be extended by the currently not considered emissions from transport, further processing in the supply chain and other emissions in the production process (e.g. $\mathrm{CO}, \mathrm{NO}_{\mathrm{x}} / \mathrm{NO}_{2}$ ). From a geographic perspective, an extension to non-European plants appears promising to create transparency for global supply chains. Based on that, a further enhancement of the case study with multiple parts from diverse industries incl. an in-depth examination of manufacturing processes and logistic chains could be interesting. The results could also be applied for the environmental assessment and supplier selection situations in industries such as the construction industry, which alone uses more than $50 \%$ of the global steel produced (World Steel Association 2017).

Summarizing, the developed approach can raise awareness within industrial companies of the environmental impact of upstream supply chain processes and create the basis for a change towards more sustainable supplier selection. Furthermore, it can support legislation on future environmental regulations, for example for the vehicle manufacturing phase similar to the use phase of cars, but also in other industrial sectors. 
Acknowledgments Open Access funding provided by Projekt DEAL.

Open Access This article is licensed under a Creative Commons Attribution 4.0 International License, which permits use, sharing, adaptation, distribution and reproduction in any medium or format, as long as you give appropriate credit to the original author(s) and the source, provide a link to the Creative Commons licence, and indicate if changes were made. The images or other third party material in this article are included in the article's Creative Commons licence, unless indicated otherwise in a credit line to the material. If material is not included in the article's Creative Commons licence and your intended use is not permitted by statutory regulation or exceeds the permitted use, you will need to obtain permission directly from the copyright holder. To view a copy of this licence, visit http://creativecommons.org/licen ses/by/4.0/.

\section{Appendix}

See Tables 6, 7, 8, 9, 10, 11, 12, 13.

Table 6 Reported production volumes (t/a) (ArcelorMittal 2013; Ruukki 2013; SSAB 2013; TATA STEEL 2013; VDEh 2014b; Voestalpine 2013; World Steel Association 2013)

\begin{tabular}{|c|c|c|c|}
\hline Prod. Site & Blast Furnace & $\begin{array}{c}\text { Basic Oxygen } \\
\text { Furnace }\end{array}$ & Rolling Mill \\
\hline 1 & $5,330,000$ & $4,340,000$ & $4,700,000$ \\
\hline 2 & $1,475,841$ & $1,370,000$ & $1,475,841$ \\
\hline 3 & $4,786,000$ & $4,343,000$ & $4,743,000$ \\
\hline 4 & $2,299,000$ & $1,893,384$ & $2,299,000$ \\
\hline 5 & $6,370,000$ & $5,990,000$ & $3,595,000$ \\
\hline 6 & $3,941,000$ & $3,888,000$ & $3,637,000$ \\
\hline 7 & $11,559,000$ & $11,419,000$ & $8,876,559$ \\
\hline 8 & $1,145,000$ & 0 & 512,000 \\
\hline 9 & $2,058,944$ & 0 & 354,949 \\
\hline 10 & $4,588,000$ & $4,273,000$ & $3,340,000$ \\
\hline 11 & $5,200,000$ & $4,620,000$ & 595,775 \\
\hline 12 & $3,200,000$ & $2,944,494$ & $3,199,000$ \\
\hline 13 & $2,272,000$ & $3,799,997$ & $1,359,936$ \\
\hline 14 & $1,800,000$ & $1,500,000$ & $1,500,000$ \\
\hline 15 & $8,076,500$ & $6,651,550$ & $8,076,500$ \\
\hline 16 & $6,600,000$ & $5,435,551$ & $4,950,000$ \\
\hline 17 & $4,276,000$ & $3,972,000$ & $3,851,000$ \\
\hline 18 & $1,927,000$ & $1,587,016$ & 0 \\
\hline 19 & 879,000 & $1,242,893$ & 532,000 \\
\hline 20 & $3,000,000$ & $3,133,660$ & $2,250,000$ \\
\hline 21 & $2,213,235$ & $1,822,750$ & 0 \\
\hline 22 & $3,100,000$ & $1,695,703$ & $2,325,000$ \\
\hline
\end{tabular}

Own assumption calculated with installed capacity on site and a ratio of company- and country specific utilization rate as well as share of capacity (VDEh, 2014a; World Steel Association, 2013)

Own assumption calculated with material conversion rates per according process step - see section 4.1 (Breun, 2016; European Commission, 2013) 
Table 7 Calculation of the energy balance for process gases reutilization on-site

\begin{tabular}{|c|c|c|}
\hline$i p g_{p s_{2}, i, l}=\{$ & $\begin{array}{l}\frac{i p g_{C O G}+i p g_{B F G a s}}{1000} \times P V_{p s_{2}, i, l} \\
\frac{i p g_{C O G}}{1000} \times P V_{p s_{2}, i, l} \\
0\end{array}$ & $\begin{array}{l}P V_{p s_{2}, i, l}>0 \wedge P V_{p s_{1}, i, l}>0 \wedge P V_{p s_{3}, i}>0 \\
P V_{p s_{2}, i, l}>0 \wedge P V_{p s_{1}, i, l}>0 \wedge P V_{p s_{3}, i, l}<0 \\
P V_{p s_{2}, i, l}=0\end{array}$ \\
\hline $\operatorname{ipg}_{p s_{2}, i, l}=$ & $\begin{array}{l}\frac{i p g_{C O G}+i p g_{B F G a s}}{1000} \times P V_{p s_{2}, i, l} \\
\frac{i p g_{C O G}}{1000} \times P V_{p s_{2}, i, l} \\
0\end{array}$ & $\begin{array}{l}P V_{p s_{2}, i, l}>0 \wedge P V_{p s_{1}, i, l}>0 \wedge P V_{p s_{3}, i}>0 \\
P V_{p s_{2}, i, l}>0 \wedge P V_{p s_{1}, i, l}>0 \wedge P V_{p s_{3}, i, l}<0 \\
P V_{p s_{2}, i, l}=0\end{array}$ \\
\hline$i p g_{p s_{4}, i, l}=$ & $\begin{array}{l}\frac{i p g_{C O G}+i p g_{B F G a s}}{1000} \times P V_{p s_{4}, i, l} \\
\frac{i p g_{C O G}}{1000} \times P V_{p s_{4}, i, l} \\
0\end{array}$ & $\begin{array}{l}P V_{p s_{4}, i, l}>0 \wedge P V_{p s_{1}, i, l}>0 \wedge P V_{p s_{3}, i, l}>0 \\
P V_{p s_{4}, i, l}>0 \wedge P V_{p s_{1}, i, l}>0 \wedge P V_{p s_{3}, i, l}<0 \\
P V_{p s_{4}, i, l}=0\end{array}$ \\
\hline $\operatorname{ipg}_{p s_{5}, i, l}=$ & $\begin{array}{l}\frac{i p g_{C O G}+i p g_{B F G a s}+i p g_{B O F G a s}}{1000} \times P \\
\frac{i p g_{C O G}+i p g_{B F G a s}}{1000} \times P V_{p s_{5}, i, l} \\
\frac{i p g_{C O G}}{1000} \times P V_{p s_{5}, i, l} \\
0\end{array}$ & $\begin{aligned} P V_{p s_{5}, i, l}, & P V_{p s_{5}, i, l}>0 \wedge P V_{p s_{1}, i, l}>0 \wedge P V_{p s_{3}, i, l}>0 \wedge B O G R_{l}=1 \\
& P V_{p s_{5}, i, l}>0 \wedge P V_{p s_{1}, i, l}>0 \wedge P V_{p s_{3}, i, l}>0 \wedge B O G R_{l}=0 \\
& P V_{p s_{5}, i, l}>0 \wedge P V_{p s_{1}, i, l}>0 \wedge P V_{p s_{3}, i, l}=0 \wedge B O G R_{l}=0 \\
& P V_{p s_{5}, i, l}=0\end{aligned}$ \\
\hline
\end{tabular}

Table 8 Average process gases (MJ/t) for reutilization on-site (Breun 2016; European Commission 2013)

\begin{tabular}{lccc}
\hline & $\begin{array}{l}\text { Coke oven gas } \\
(\mathrm{COG})\end{array}$ & $\begin{array}{l}\text { Blast furnace gas (BF } \\
\text { gas) }\end{array}$ & $\begin{array}{l}\text { Basic oxygen } \\
\text { furnace gas (BOF } \\
\text { gas) }\end{array}$ \\
\hline Output & 7888 & 4572 & 458 \\
Input & 562 & 2892 & 287 \\
Coke oven & 31 & 29 & 130 \\
Sintering plant & 361 & 1599 & \\
Blast furnace & 446 & 18 & 37 \\
Basic oxygen furnace & 735 & 186 & 37 \\
Rolling mill & &
\end{tabular}

Table 9 Average emission factors $\left(\mathrm{tCO}_{2} / \mathrm{t}\right)$ per intermediate products (Breun 2016; European Commission 2013)

\begin{tabular}{ll}
\hline Process step & Emission factor \\
\hline Coke oven (coke) & 0.68 \\
Sintering plant (sinter) & 0.27 \\
Blast furnace (pig iron) & 0.50 \\
Basic oxygen furnace (crude steel) & 0.12 \\
Rolling mill (rolled steel) & 0.15 \\
Power plant (pig iron) & 0.87 \\
\hline
\end{tabular}




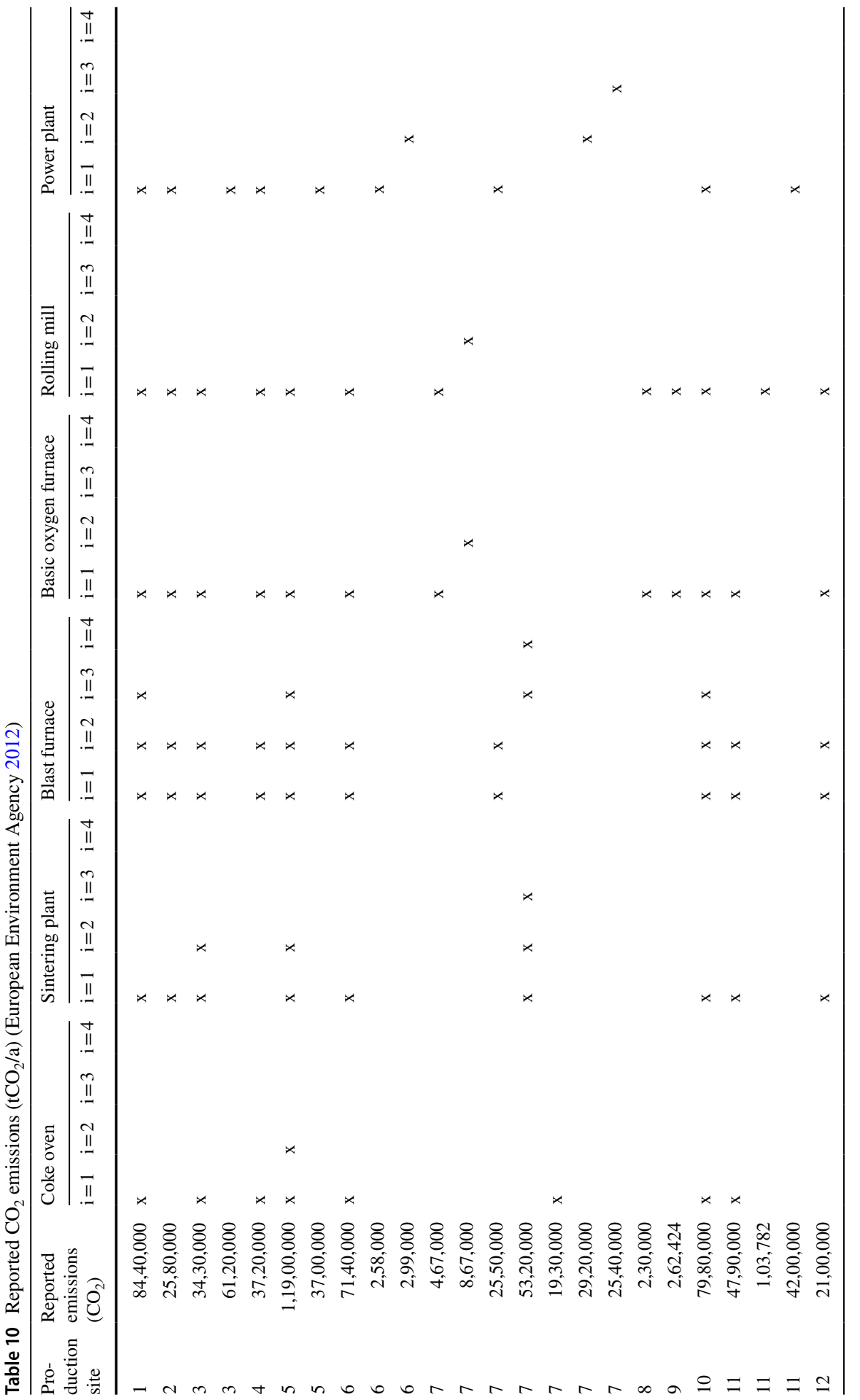




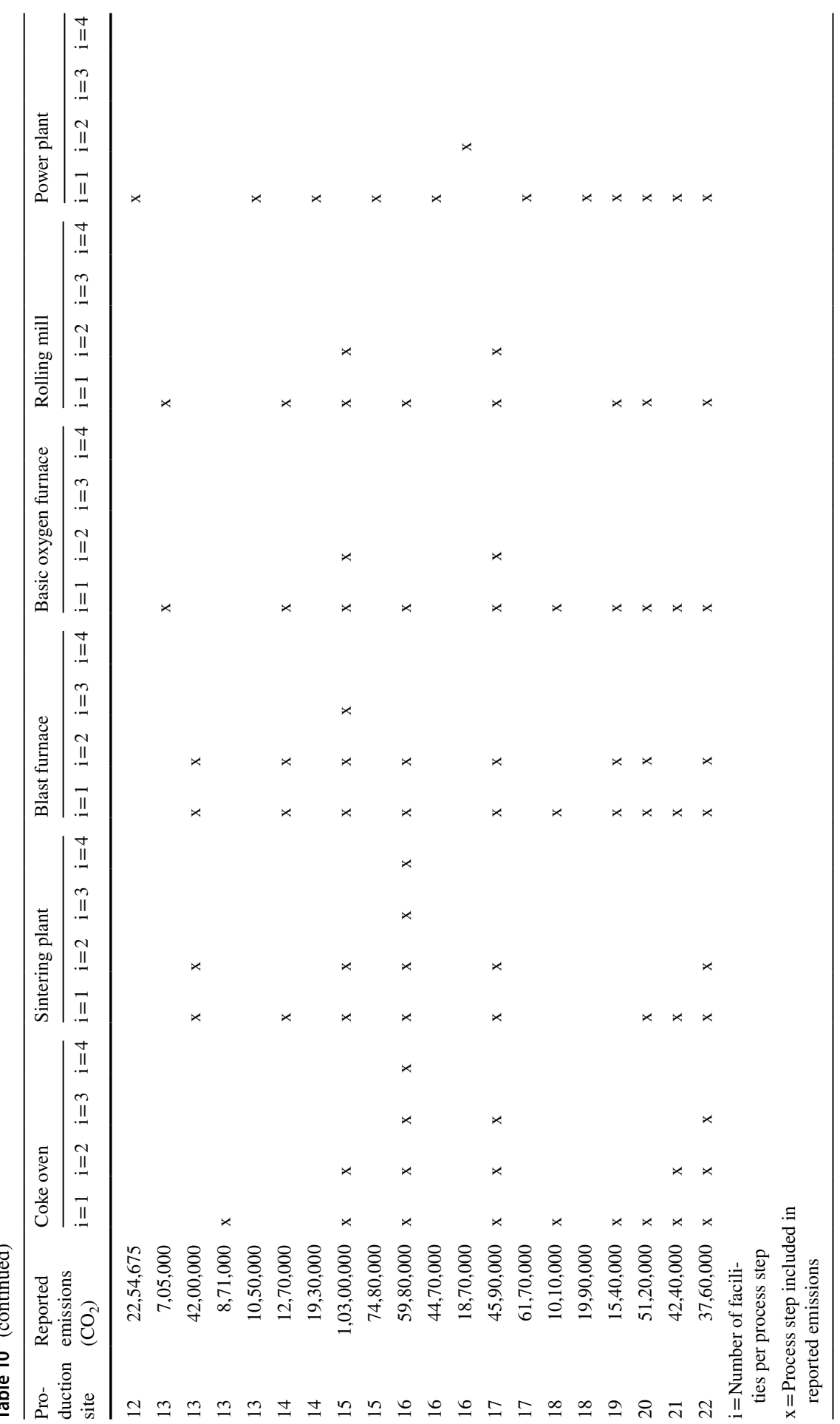


Table 11 Simulation of fully integrated steel mills, producing everything on-site

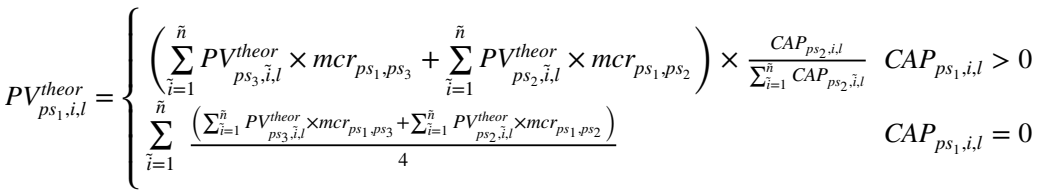

$$
\begin{aligned}
& P V_{p s_{2}, i, l}^{\text {theor }}= \begin{cases}\sum_{\tilde{i}=1}^{\tilde{n}} P V_{p s_{3}, \tilde{i}, l}^{\text {theor }} \times m c r_{p s_{2}, p s_{3}} \times \frac{C A P_{p s_{2}, \tilde{i}, l}}{\sum_{i=1}^{\tilde{n}} C A P_{p s_{2}, i, l}}, & C A P_{p s_{2}, i, l}>0 \\
\sum_{\tilde{i}=1}^{\tilde{n}} \frac{P V_{p s_{3}, i, l}^{\text {theor }} \times m c r_{p s_{2}, p s_{3}}}{4}, & C A P_{p s_{2}, i, l}=0\end{cases} \\
& P V_{p s_{4}, i, l}^{\text {theor }}=P V_{p s_{4}, i, l}
\end{aligned}
$$

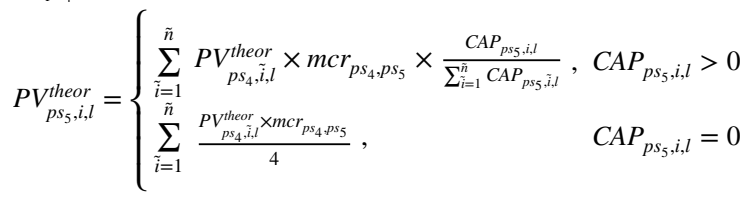




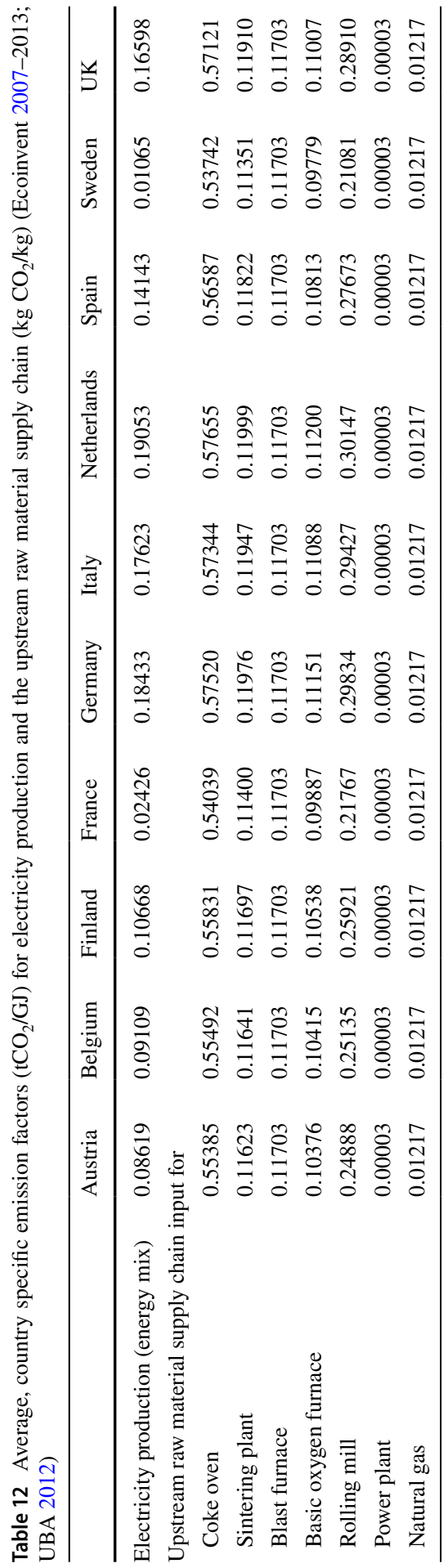




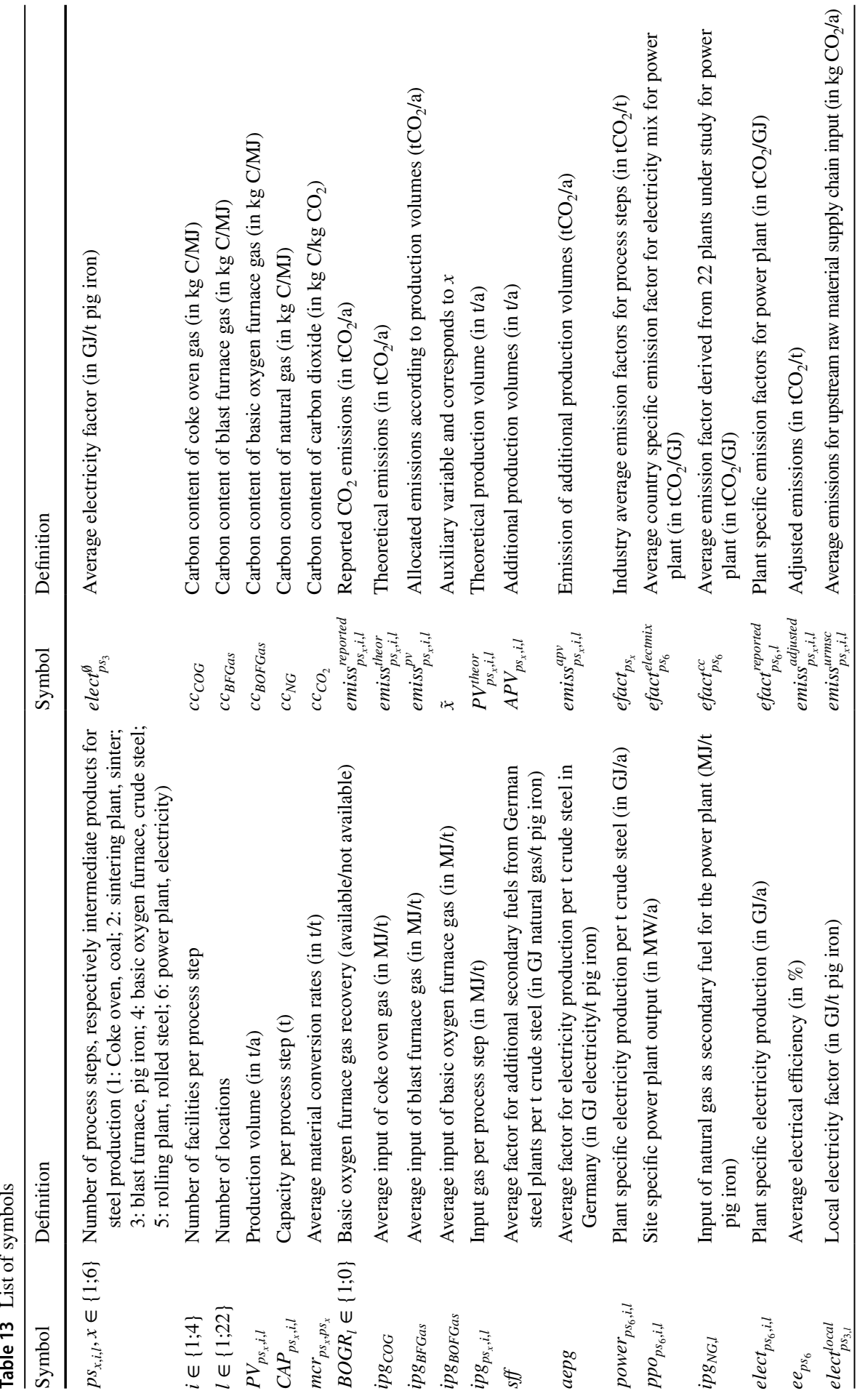




\section{References}

Aczél J, Saaty TL (1983) Procedures for synthesizing ratio judgements. J Math Psychol 27:93-102

Ahi P, Searcy C (2015) An analysis of metrics used to measure performance in green and sustainable supply chains. J Clean Prod 86:360-377

ArcelorMittal (2013) Factbook 2013. https://corporate.arcelormittal.com/ /media/Files/A/ArcelorMit tal/investors/fact-book/arcelormittal_ar2013_factbook.pdf. Accessed 10 Sept 2018

Arikan F (2015) An interactive solution approach for multiple objective supplier selection problem with fuzzy parameters. J Intell Manuf 26:989-998

Azadnia AH, Saman MZM, Wong KY (2015) Sustainable supplier selection and order lot-sizing: an integrated multi-objective decision-making process. Int J Prod Res 53:383-408

Bai C, Sarkis J (2011) Evaluating supplier development programs with a grey based rough set methodology. Expert Syst Appl 38:13505-13517

Bauer C, Poganietz WR (2007) Prospektive Lebenszyklusanalyse oder die Zukunft in der Okobilanz. Zeitschrift für Technikfolgenabschätzung in Theorie und Praxis 16:17-23

Bieda B (2014) Application of stochastic approach based on Monte Carlo (MC) simulation for life cycle inventory (LCI) to the steel process chain: case study. Sci Total Environ 481:649-655

Bieda B, Grzesik K, Sala D, Gaweł B (2015) Life cycle inventory processes of the integrated steel plant (ISP) in Krakow, Poland-coke production, a case study. Int J Life Cycle Assess 20:1089-1101

Bilec M, Ries R, Matthews HS, Sharrard AL (2006) Example of a hybrid life-cycle assessment of construction processes. J Infrastruct Syst 12:207-215

BMJV (2013) Vierte Verordnung zur Durchführung des Bundes- Immissionsschutzgesetzes (Verordnung über genehmigungsbedürftige Anlagen-4. BImSchV). Bundesministeriums der Justiz und für Verbraucherschutz

Boosothonsatit K, Kara S, Ibbotson S (2012) A Generic Simulation Model for Green Supplier Selection. In: Dornfeld DA, Linke BS (eds) Leveraging technology for a sustainable world. Proceedings of the 19th CIRP conference on life cycle engineering, University of California at Berkeley, Berkeley, USA, May 23-25, 2012; LCE 2012. Springer, Berlin, pp 587-592

Brander M (2017) Comparative analysis of attributional corporate greenhouse gas accounting, consequential life cycle assessment, and project/policy level accounting: a bioenergy case study. J Clean Prod 167:1401-1414

Breun P (2016) Ein Ansatz zur Bewertung klimapolitischer Instrumente am Beispiel der Metallerzeugung und -verarbeitung. KIT Scientific Publishing, Karlsruhe

Breun P, Fröhling M, Zimmer K, Schultmann F (2017) Analyzing investment strategies under changing energy and climate policies. An interdisciplinary bottom-up approach regarding German metal industries. J Bus Econ 87:5-39

Brunke J-C, Blesl M (2014) A plant-specific bottom-up approach for assessing the cost-effective energy conservation potential and its ability to compensate rising energy-related costs in the German iron and steel industry. Energy Policy 67:431-446

Bruno G, Esposito E, Genovese A, Passaro R (2012) AHP-based approaches for supplier evaluation: problems and perspectives. J Purch Supply Manag 18:159-172

Burchart-Korol D (2011) Significance of environmental life cycle assessment (LCA) method in the iron and steel industry. Metalurgija 50:205-208

Burchart-Korol D (2013) Life cycle assessment of steel production in Poland. A case study. J Clean Prod 54:235-243

Büyüközkan G (2012) An integrated fuzzy multi-criteria group decision-making approach for green supplier evaluation. Int J Prod Res 50:2892-2909

Chai J, Liu JNK, Ngai EWT (2013) Application of decision-making techniques in supplier selection: a systematic review of literature. Expert Syst Appl 40:3872-3885

Cullen JM, Allwood JM, Bambach MD (2012) Mapping the global flow of steel: from steelmaking to end-use goods. Environ Sci Technol 46:13048-13055

Das B, Prakash S, Reddy PSR, Misra VN (2007) An overview of utilization of slag and sludge from steel industries. Resour Conserv Recycl 50:40-57

Dong Y, Miraglia S, Manzo S, Georgiadis S, Sørup HJD, Boriani E, Hald T, Thöns S, Hauschild MZ (2018) Environmental sustainable decision making- The need and obstacles for integration of LCA into decision analysis. Environ Sci Policy 87:33-44 
Dowlatshahi S (2000) Designer-buyer-supplier interface: theory versus practice. Int J Prod Econ 63:111-130

Ecoinvent (2007-2013) Ecoinvent Data V2.2. The life cycle inventory data version. Swiss Centre for Life Cycle Inventories, St. Gallen

EPSC (2016) Towards low-emission mobility. Driving the modernisation of the EU economy. European Political Strategy Centre, Brussels

European Commission (2006) Regulation (EC) No 166/2006. Off J Eur Union L33:1-17

European Commission (2009) Regulation (EC) No 443/2009. Off J Eur Union L140:1-15

European Commission (2010) Directive 2010/75/EU of the European Parliament and of the Council of 24 November 2010 on industrial emissions (integrated pollution prevention and control). Off J Eur Union L334:17-119

European Commission (2013) Best available techniques (BAT) Reference document for iron and steel production industrial emissions directive 2010/75/EU (Integrated Pollution Prevention and Control). European Integrated Pollution Prevention and Control Bureau (EIPPCB)

European Commission (2018) EU transport in figures-Statistical pocketbook 2018. Statistical pocketbook 2018. Publications office of the European Union, Luxembourg

European Commission (2019) Regulation (EU) 2019/631. Off J Eur Union L111:13-53

European Environment Agency (2012) The European Pollutant Release and Transfer Register (E-PRTR), Member States reporting under Article 7 of Regulation (EC) No 166/2006. Database

Forman E, Peniwati K (1998) Aggregating individual judgments and priorities with the analytic hierarchy process. Eur J Oper Res 108:165-169

Fox WP, Ormond B, Williams A (2015) Ranking terrorist targets using a hybrid AHP-TOPSIS methodology. J Def Model Simul Appl Methodol Technol 13:77-93

Gabi (2017) Version 8.1. GaBi software-System and Database for Life Cycle Engineering. Thinkstep, A.G., Leinfelden-Echterdingen

Gawel E (2011) Kfz-Steuer-Reform und Klimaschutz. Wirtschaftsdienst 91:137-143

Gielen D, Moriguchi Y (2002) $\mathrm{CO}_{2}$ in the iron and steel industry: an analysis of Japanese emission reduction potentials. Energy Policy 30:849-863

Govindan K, Rajendran S, Sarkis J, Murugesan P (2015) Multi criteria decision making approaches for green supplier evaluation and selection: a literature review. J Clean Prod 98:66-83

Grošelj P, Zadnik Stirn L, Ayrilmis N, Kuzman MK (2015) Comparison of some aggregation techniques using group analytic hierarchy process. Expert Syst Appl 42:2198-2204

Guinée JB, Heijungs R, Udo de Haes HA, Huppes G (1993) Quantitative life cycle assessment of products. J Clean Prod 1:81-91

Guinée JB, Heijungs R, Huppes G, Zamagni A, Masoni P, Buonamici R, Ekvall T, Rydberg T (2011) Life cycle assessment: past, present, and future. Environ Sci Technol 45:90-96

Hanine M, Boutkhoum O, Tikniouine A, Agouti T (2016) Application of an integrated multi-criteria decision making AHP-TOPSIS methodology for ETL software selection. SpringerPlus 5:263

Hartley JL, Choi TY (1996) Supplier development. Customers as a catalyst of process change. Bus Horiz 39:37-44

Hashemi SH, Karimi A, Tavana M (2015) An integrated green supplier selection approach with analytic network process and improved Grey relational analysis. Int J Prod Econ 159:178-191

Heijungs R, Guinée JB, Huppes G, Lankreijer RM, Udo de Haes HA, Wegener Sleeswijk A, Ansems AMM, Eggels PG, van Duin R, de Goede HP (1992) Environmental life cycle assessment of products: guide and backgrounds (part 1). Centre of Environmental Science (CML), Leiden

Hendrickson CT, Horvath A, Joshi S, Klausner M, Lave LB, McMichael FC (1997) Comparing two life cycle assessment approaches. A process model vs. economic input-output-based assessment. In: Proceedings of the 1997 IEEE international symposium on electronics and the environment, ISEE, 1997. May 5-7, 1997, San Francisco, California. Institute of Electrical and Electronics Engineers; Available from IEEE Service Center, [New York, N.Y.], Piscataway, pp 176-181

Hsu C-W, Kuo T-C, Chen S-H, Hu AH (2013) Using DEMATEL to develop a carbon management model of supplier selection in green supply chain management. J Clean Prod 56:164-172

Huang Z, Ding X, Sun H, Liu S (2010) Identification of main influencing factors of life cycle $\mathrm{CO}_{2}$ emissions from the integrated steelworks using sensitivity analysis. J Clean Prod 18:1052-1058

Huang X, Wang Z, Liu Y, Hu W, Ni W (2016) On the use of blast furnace slag and steel slag in the preparation of green artificial reef concrete. Constr Build Mater 112:241-246

Hwang C-L, Yoon K (1981) Multiple attribute decision making. Methods and applications a state-of-theart survey. Springer, Berlin 
Igarashi M, de Boer L, Fet AM (2013) What is required for greener supplier selection? A literature review and conceptual model development. J Purch Supply Manag 19:247-263

International Standards Organisation (2006a) ISO 14040: environmental management—life cycle assessment- principles and framework, Geneva

International Standards Organisation (2006b) ISO 14044: environmental management-life cycle assessment-requirements and guidelines, Geneva

Jaeger C, Jaeger J (2010) Three views of two degrees. Clim Change Econ 01:145-166

Karsak EE, Dursun M (2016) Taxonomy and review of non-deterministic analytical methods for supplier selection. Int J Comput Integr Manuf 29:263-286

Kim DY, Wagner SM (2012) Supplier selection problem revisited from the perspective of product configuration. Int J Prod Res 50:2864-2876

Klöpffer W (2012) The critical review of life cycle assessment studies according to ISO 14040 and 14044. Int J Life Cycle Assess 17:1087-1093

Kndungu P, Molavi JM (2014) A hybrid LCA approach to quantify the environmental impacts during construction. IJIRSET 03:16402-16413

Kumar A, Jain V, Kumar S (2014) A comprehensive environment friendly approach for supplier selection. Omega 42:109-123

Leonelli R (2012) Enhancing a decision support tool with sensitivity analysis. University of Manchester, Manchester

Leontief WW (1936) Quantitative input and output relations in the economic systems of the United States. Rev Econ Stat 18:105

Lieberwirth H, Krampitz T (2015) Entwicklungstendenzen für den Einsatz von Leichtbauwerkstoffen im Fahrzeugbau und Auswirkungen auf das Recycling. Recycling und Rohstoffe 8:207-218

Magerholm Fet A (ed) (1998) Environmental management tools and their application-a review with reference to case studies. In: 2nd international conference on technology policy and innovation

Nielsen IE, Banaeian N, Golińska P, Mobli H, Omid M (2014) Green supplier selection criteria: from a literature review to a flexible framework for determination of suitable criteria. In: Golinska P (ed) Logistics operations, supply chain management and sustainability. Springer, Cham, pp 79-99

Ossadnik W, Schinke S, Kaspar RH (2016) Group aggregation techniques for analytic hierarchy process and analytic network process: a comparative analysis. Group Decis Negot 25:421-457

Pfeifer H, Hogner W, Fredriksson P, Scheele J, von Paul R (2009) Warme und Energie-Energieeffizienz und Minderung des $\mathrm{CO}_{2}$-Ausstosses durch Sauerstoffverbrennung. stahl und eisen 129:51

Roy P, Nei D, Orikasa T, Xu Q, Okadome H, Nakamura N, Shiina T (2009) A review of life cycle assessment (LCA) on some food products. J Food Eng 90:1-10

Ruukki (2013) Financial Statement Bulletin 1 Jan-31 Dec 2012. https://www.ssab.pl/globaldata/ruukk i-financial-news-archive/2013/2/15/ /media/5E62E3348BDD471189DA3968C63C4E23.ashx. Accessed 13 May 2019

S\&P Global Platts (2015) World electric power plants database. https://www.spglobal.com/platts/en/ products-services/electric-power/world-electric-power-plants-database. Accessed 13 May 2019

Saaty TL (1980) The analytic hierarchy process. Planning, priority setting, resource allocation. McGrawHill, New York

Saaty RW (1987) The analytic hierarchy process—-what it is and how it is used. Math Model 9:161-176

Saaty TL (1989) Group decision making and the AHP. In: Golden BL, Wasil EA, Harker PT (eds) The analytic hierarchy process. Applications and studies. Springer, Berlin, pp 59-67

Saaty TL (2001) Decision making for leaders. The analytic hierarchy process for decisions in a complex world, new edition printing, 3rd edn. RWS Publ, Pittsburgh

Schmid D, Zur-Lage L (2014) Perspektiven für das Recycling von Altfahrzeugen. Recycling und Rohstoffe 7:105-126

Science Based Targets Initiative (2015) SECTORAL DECARBONIZATION APPROACH (SDA): a method for setting corporate emission reduction targets in line with climate science. https://scien cebasedtargets.org/wp-content/uploads/2015/05/Sectoral-Decarbonization-Approach-Report.pdf. Accessed 13 May 2019

Seuring S, Müller M (2008) From a literature review to a conceptual framework for sustainable supply chain management. J Clean Prod 16:1699-1710

Shih H-S, Shyur H-J, Lee ES (2007) An extension of TOPSIS for group decision making. Math Comput Model 45:801-813

Siddique R (2014) Utilization of industrial by-products in concrete. Procedia Eng 95:335-347 
Singh A (2014) Supplier evaluation and demand allocation among suppliers in a supply chain. J Purch Supply Manag 20:167-176

Sonnemann G, Castells F, Schuhmacher M (2004) Integrated life-cycle and risk assessment for industrial processes. Lewis Publishers, Boca Raton

SSAB (2013) Sustainability report 2012. https://ssabwebsitecdn.azureedge.net/-/media/files/company/ sustainability/sustainability-reports/2012/sustainability_report_2012_en.pdf?m=20151021084324. Accessed 13 May 2019

Suh S, Lenzen M, Treloar GJ, Hondo H, Horvath A, Huppes G, Jolliet O, Klann U, Krewitt W, Moriguchi Y, Munksgaard J, Norris G (2004) System boundary selection in life-cycle inventories using hybrid approaches. Environ Sci Technol 38:657-664

Suraraksa J, Shin K (2019) Comparative analysis of factors for supplier selection and monitoring: the case of the automotive industry in Thailand. Sustainability 11:981

Tanaka K (2012) A comparison study of EU and Japan methods to assess CO2 emission reduction and energy saving in the iron and steel industry. Energy Policy 51:578-585

TATA STEEL (2013) 106th Annual Report 2012-2013. https://www.tatasteel.com/investors/annual-repor t-2012-13/html/pdf/Tata\%20Steel\%20Annual\%20Report\%2012-13.pdf. Accessed 13 May 2019

Thyssenkrupp AG (2018) The Carbon2Chem ${ }^{\circledR}$ project. www.thyssenkrupp.com/de/carbon2chem/. Accessed 13 May 2019

Triantaphyllou E, Sánchez A (1997) A sensitivity analysis approach for some deterministic multi-criteria decision-making methods. Decis Sci 28:151-194

UBA (2012) Carbon Footprint-Teilgutachten. "Monitoring für den $\mathrm{CO}_{2}$-Ausstoß in der Logistikkette". https://www.umweltbundesamt.de/sites/default/files/medien/461/publikationen/4306.pdf. Accessed 13 May 2019

UBA (2014) Schätzung der Umweltkosten in den Bereichen Energie und Verkehr. https://www.umwel tbundesamt.de/sites/default/files/medien/378/publikationen/hgp_umweltkosten_0.pdf. Accessed 13 May 2019

UBA (2016) Weiterentwicklung und vertiefte Analyse der Umweltbilanz von Elektrofahrzeugen. Federal Ministry for the Environment, Nature Conservation and Nuclear Safety, Bonn

UBA (2018a) Emissionen aus Betrieben der Metallindustrie. https:/www.umweltbundesamt.de/daten/ umwelt-wirtschaft/industrie/emissionen-aus-betrieben-der-metallindustrie\#textpart-1. Accessed 13 May 2019

UBA (2018b) Emissions trading. https://www.bmu.de/en/topics/climate-energy/emissions-trading/. Accessed 13 May 2019

VDEh (2013) Beitrag der Stahlindustrie zu Nachhaltigkeit, Ressourcen-und Energieeffizienz. Stahleisen, Düsseldorf

VDEh (2014a) PLANTFACTS database. Stahleisen, Düsseldorf

VDEh (2014b) Statistisches Jahrbuch der Stahlindustrie 2013/2014. Stahleisen, Düsseldorf

Verma R, Pullman ME (1998) An analysis of the supplier selection process. Omega 26:739-750

Voestalpine (2013). Umwelterklärung 2013. https://www.voestalpine.com/group/static/sites/group/.downl oads/de/konzern/2013-umwelterklaerung.pdf. Accessed 13 May 2019

Volkswagen AG (2019) Volkswagen ID. will be a pioneer of sustainable mobility. www.volkswagen -newsroom.com/en/press-releases/volkswagen-id-will-be-a-pioneer-of-sustainable-mobility-4649. Accessed 13 May 2019

Weidema BP (1993) Market aspects in product life cycle inventory methodology. J Clean Prod 1:161-166

Weidema BP (2003) Market information in life cycle assessment. Danish environmental protection agency, Miljøstyrelsen

World Steel Association (2013) Steel statistical yearbook 2013. https://www.worldsteel.org/en/dam/ jcr:7bb9ac20-009d-4c42-96b6-87e2904a721c/Steel-Statistical-Yearbook-2013.pdf. Accessed 11 Jan 2020

World Steel Association (2017) STEEL IN BUILDINGS AND INFRASTRUCTURE. https://www.world steel.org/steel-by-topic/steel-markets/buildings-and-infrastructure.html. Accessed 10 June 2019

World Steel Association (2019) FACT SHEET. Energy use in the steel industry. https://www.worldsteel .org/en/dam/jcr:f07b864c-908e-4229-9f92-669f1c3abf4c/fact_energy_2019.pdf. Accessed 11 Jan 2020

Worrell E, van Gent P, Neelis M, Blomen E, Masanet E (2009) Energy efficiency improvement and cost saving opportunities for the US Iron and Steel Industry an ENERGY STAR(R) Guide for Energy and Plant Managers. Ernest Orlando Lawrence Berkeley National Laboratory, Berkley 
Yellishetty M, Mudd GM, Ranjith PG, Tharumarajah A (2011) Environmental life-cycle comparisons of steel production and recycling. Sustainability issues, problems and prospects. Environ Sci Policy 14:650-663

Yoshizaki Y, Yamada T, Itsubo N, Inoue M (2014) Material based low-carbon and economic supplier selection with estimation of $\mathrm{CO}_{2}$ emissions and cost using life cycle inventory database. Innov Supply Chain Manag 8:159-170

Zamagni A, Pesonen H-L, Swarr T (2013) From LCA to life cycle sustainability assessment. concept, practice and future directions. Int J Life Cycle Assess 18:1637-1641

Zhou M, Han S, Wang L, Jiang X, Xu L, Zhai L, Liu J, Zhang H, Qin X, Shen F (2015) Effect of size distribution of coke breeze on sintering performance. Steel Res Int 86:1242-1251

Zimmer K (2016) Entscheidungsunterstützung zur Auswahl und Steuerung von Lieferanten und Lieferketten unter Berücksichtigung von Nachhaltigkeitsaspekten. KIT Scientific Publishing, Karlsruhe

Zimmer K, Fröhling M, Schultmann F (2016) Sustainable supplier management - a review of models supporting sustainable supplier selection, monitoring and development. Int J Prod Res 54:1412-1442

Zimmer K, Fröhling M, Breun P, Schultmann F (2017) Assessing social risks of global supply chains: a quantitative analytical approach and its application to supplier selection in the German automotive industry. J Clean Prod 149:96-109

Publisher's Note Springer Nature remains neutral with regard to jurisdictional claims in published maps and institutional affiliations.

\section{Affiliations}

\section{Andreas Schiessl ${ }^{1}$ (D) $\cdot$ Richard Müller $^{1} \cdot$ Rebekka Volk $^{1} \cdot$ Konrad Zimmer $^{1}$. Patrick Breun ${ }^{1}$. Frank Schultmann ${ }^{1}$}

Andreas Schiessl

Andreas.schiess1@partner.kit.edu

1 Karlsruhe Institute of Technology (KIT), Institute for Industrial Production (IIP), Hertzstraße 16, 76187 Karlsruhe, Germany 